Nova Southeastern University

Florida

NOVA SOUTHEASTERN

UNIVERSTYY

NSUWorks

Marine \& Environmental Sciences Faculty Articles Department of Marine and Environmental Sciences

6-1-1997

\title{
Sharp Frontal Interfaces in the Near-Surface Layer of the Ocean in the Western Equatorial Pacific Warm Pool
}

\author{
Alexander Soloviev \\ University of Hawaii - Manoa, soloviev@nova.edu \\ Roger Lukas \\ University of Hawaii - Manoa \\ Find out more information about Nova Southeastern University and the Halmos College of Natural Sciences \\ and Oceanography.
}

Follow this and additional works at: https://nsuworks.nova.edu/occ_facarticles

Part of the Marine Biology Commons, and the Oceanography and Atmospheric Sciences and Meteorology Commons

\section{NSUWorks Citation}

Alexander Soloviev and Roger Lukas. 1997. Sharp Frontal Interfaces in the Near-Surface Layer of the Ocean in the Western Equatorial Pacific Warm Pool .Journal of Physical Oceanography, (6) : 999 -1017. https://nsuworks.nova.edu/occ_facarticles/630.

This Article is brought to you for free and open access by the Department of Marine and Environmental Sciences at NSUWorks. It has been accepted for inclusion in Marine \& Environmental Sciences Faculty Articles by an authorized administrator of NSUWorks. For more information, please contact nsuworks@nova.edu. 


\title{
Sharp Frontal Interfaces in the Near-Surface Layer of the Ocean in the Western Equatorial Pacific Warm Pool
}

\author{
Alexander Soloviev* AND Roger LuKas \\ Department of Oceanography, University of Hawaii at Manoa, Honolulu, Hawaii
}

(Manuscript received 30 March 1995, in final form 8 November 1996)

ABSTRACT

\begin{abstract}
During the TOGA COARE rich horizontal temperature and salinity variability of the near-surface layer of the ocean in the western Pacific warm pool was observed. High-resolution measurements were made by probes mounted on the bow of the vessel in an undisturbed region at $\sim 1.7-\mathrm{m}$ depth during four COARE cruises of the R/V Moana Wave. The authors observed several tens of cases of periodic sharp frontal interfaces of width 1$100 \mathrm{~m}$ and separation $0.2-60 \mathrm{~km}$. The sharp frontal interfaces were often found in frontal regions and on the periphery of freshwater puddles. Maneuvers of the ship were conducted to determine the spatial orientation of a sharp frontal interface. The interfaces revealed anisotropy with respect to the wind direction. They were most sharp when the wind stress had a component along the buoyant spreading of the front. A possible origin of the sharp frontal interfaces is discussed. These interfaces may develop by nonlinear evolution of long-wave disturbances on the near-surface pycnocline that is often observed in the warm pool area. A shallow-water model may describe some features of the observations. A dimensionless number of the Reynolds type is a criterion of transition from wave train solution to dissipative shock-wave structure. The model predicts spatial anisotropy depending on the relative angle between the wind stress and horizontal density gradient.
\end{abstract}

\section{Introduction}

Understanding of the dynamics of the near-surface layer of the ocean in the western equatorial Pacific warm pool is crucial for good simulation of certain important features of the ENSO (Lukas and Lindstrom 1991; Webster and Lukas 1992). The warm pool area is characterized by considerable thermohaline stratification of the near-surface layer of the ocean. Deep well-mixed profiles are rare and seem to be observed only following westerly wind bursts. The so-called barrier layer is often observed in the warm pool between the base of the shallow mixed layer and the top of the relatively deep thermocline (Lukas and Lindstrom 1991). Figure 1 shows profiles of the multilayer structure of the upper ocean in the warm pool area. The barrier layer is observed within the pressure (depth) range from 15 to 130 dbar. Note the near-surface pycnocline is within the range 15-35 dbar.

Anderson et al. (1996) demonstrated that the barrier layer might be maintained by rain-caused freshwater

*Current affiliation: Oceanographic Center, Nova Southeastern University, Dania, Florida.

Corresponding author address: Dr. Alexander V. Soloviev, NOVA Southeastern University's Oceanographic Center, 8000 North Ocean Dr., Dania, FL 33004.

E-mail: soloviev@ocean.nova.edu influx and prevailing relatively calm weather conditions in the warm pool area. Rainfall forms a shallow, fresh, stable layer that damps turbulent mixing in the surface layer of the ocean. The initial freshness of the layer makes it so buoyant that nighttime surface cooling and accompanying convection are not able to initiate its mixing with the water below. On successive days the shallow surface layer traps daytime heating, additionally increasing its stability.

Far less is known about the spatial structure of the near-surface layer of the ocean in the warm pool area. The 1-km resolution dataset of Huyer et al. (1996) shows that the thermohaline fields in the warm pool area are heterogeneous and nonstationary to a surprising degree. There are numerous instances of mesoscale and submesoscale fronts in the surface layer of the warm pool area (Shinoda et al. 1995). Numerical simulations of the tropical Pacific Ocean show the importance of the oceanic fronts in forming the barrier layer (Shinoda and Lukas 1995; Ando and McPhaden 1995; Vialard and Delecluse 1996, manuscript submitted to $J$. Phys. Oceanogr., hereafter VD97).

The high-resolution measurements during the TOGA COARE (Soloviev et al. 1995) revealed a pronounced horizontal thermohaline variability in the near-surface layer of the ocean associated with the presence of the near-surface stratification. An interesting feature of the horizontal structure is an occasional series of sharp frontal interfaces of width 1-100 m and separation $0.2-60$ 


\section{a) $\quad$ CTD $\quad 0_{.50}^{\circ} \mathrm{S} \quad 1^{165.01}{ }^{\circ} \mathrm{E} \quad$ 05:32UTC 16 April 1994}
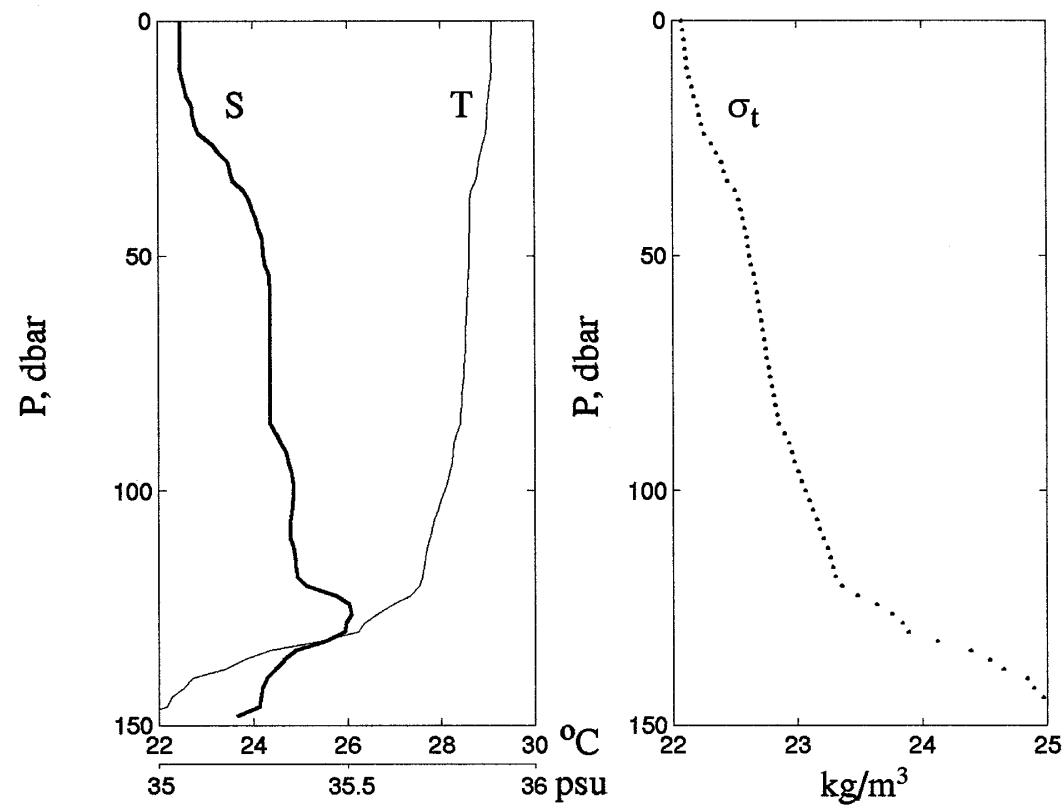

b)

FRP $0.51^{\circ} \mathrm{S}$

\section{$165.00^{\circ} \mathrm{E}$}

\section{3:56UTC}

16 April 1994
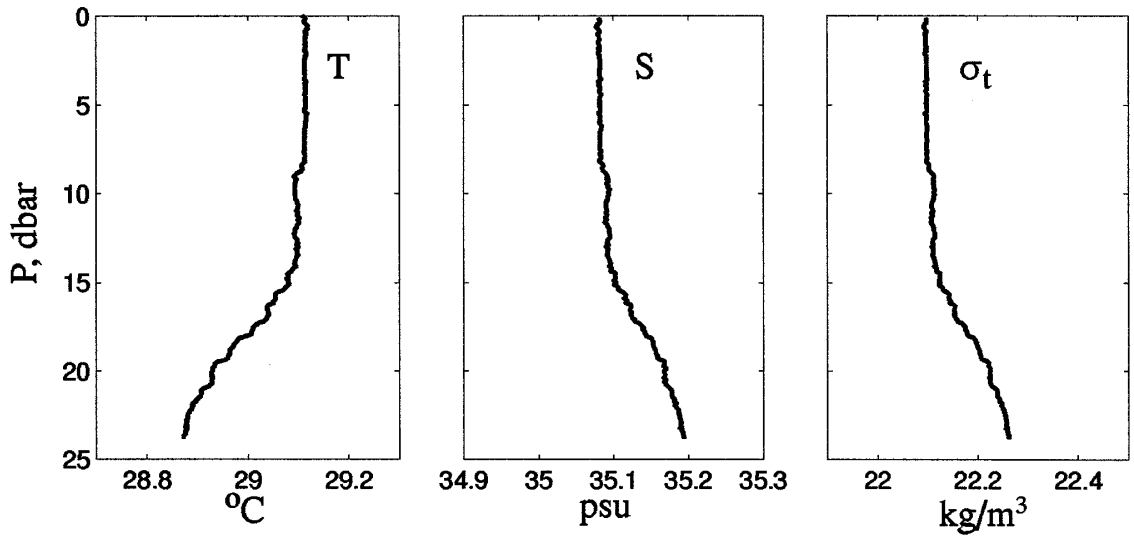

FIG. 1. An example of the vertical structure of the upper ocean in the warm pool area. (a) CTD profiles of temperature $T$, salinity $S$, and density $\sigma_{t}$ in the upper layer of the ocean in the warm pool area (Shinoda et al. 1995); (b) $T, S$, and $\sigma_{t}$ in the upper $25 \mathrm{~m}$ of the ocean obtained by a free-rising profiler (FRP) (Soloviev et al. 1995). Wind speed 7.6-8.8 $\mathrm{m} \mathrm{s}^{-1}$.

$\mathrm{km}$ between adjacent interfaces. Figure 2 shows an example of such a structure. During the TOGA COARE we observed several tens of such structures. They are different from the so-called ramplike structures (Thorpe 1985; Soloviev 1990) but have some similarity with the internal surge or internal bore structures previously observed in long stably stratified lakes (Thorpe 1971; Thorpe et al. 1972; Hunkins and Fliegel 1973; Farmer 1978).
Several factors limit observation of the sharp frontal interfaces. The sharp frontal interfaces are very localized in space and the moments of their intersection are unknown in advance. For their study, a high-resolution measurement over a relatively long time period is therefore necessary. There are no conventional techniques for such measurements. Moreover, the magnitude of the cross-frontal difference in temperature $(T)$ and salinity $(S)$ is typically only of the order of several hundredths 


\section{2:33 UTC 20 Apr 94 - 11:44 UTC 21 Apr 94}
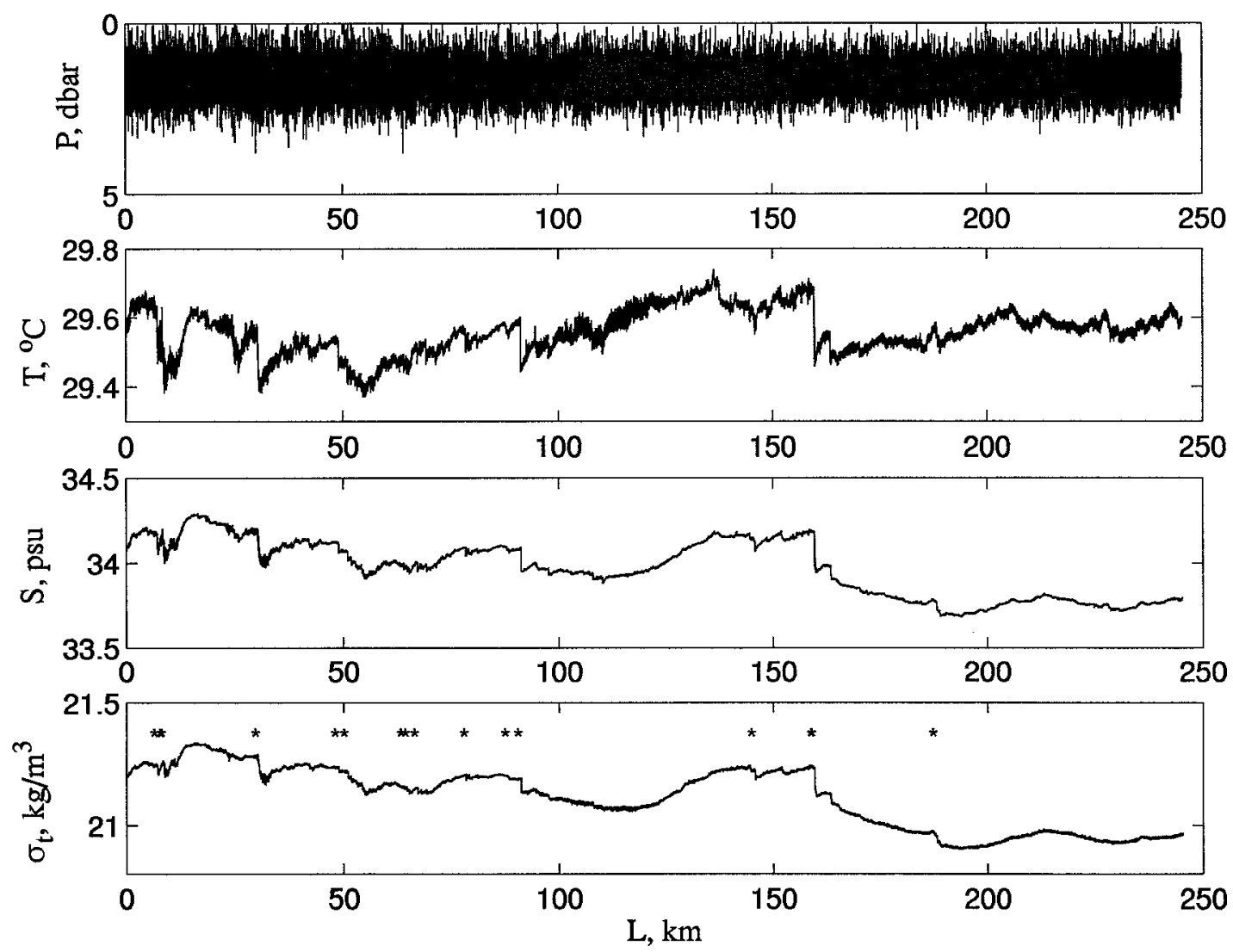

FIG. 2. Example of repeating asymmetrical structure in the near-surface layer of the ocean in the western equatorial Pacific warm pool. This is a 13 -h record obtained by bow sensors from $7^{\circ} 04^{\prime} 31^{\prime \prime} \mathrm{S}, 164^{\circ} 21^{\prime} 14^{\prime \prime} \mathrm{E}$ to $5^{\circ} 00^{\prime} 07^{\prime \prime} \mathrm{S}, 163^{\circ} 12^{\prime} 10^{\prime \prime} \mathrm{E}$ (ship direction $\sim 330^{\circ}$ ). Sharp frontal interfaces detected on $\sigma_{t}$ by the algorithm described in appendix A are marked by asterisks. Detailed plots of the marked areas are given in Fig. 3.

of a degree or psu. Such frontal interfaces are strongly masked by the diurnal warming or precipitation effects in the near-surface layer of the ocean. In measurements by anchored sensors, the sharp frontal interfaces can be detected only for extreme situations; the frequency range of the signal from the sharp frontal interfaces is substantially overlapped by the frequency range of the diurnal warming/precipitation variability. The towed measurements, however, do reveal the sharp frontal interfaces because of the horizontal scale separation.

Previously, Zenk and Katz (1975) reported observations of a sharp frontal interface in the Sargasso Sea. A 26-m depth tow segment revealed the temperature interface with a gradient of $6.8^{\circ} \mathrm{C} \mathrm{km}$. This frontal feature extended up to the ocean surface where its intersection was registered by the ship's hull sensor. Observations from the Space Shuttle Atlantis using a telephoto lens (Yoder et al. 1994) reveal narrow frontal lines on the ocean surface in the equatorial Pacific. Soloviev and Zatsepin (1992) observed the sharp frontal interfaces in the equatorial Atlantic and in the Azores
Front, using bow sensors similar to those we used for the TOGA COARE.

The purpose of this paper is to describe the sharp frontal interfaces observed in the western equatorial $\mathrm{Pa}-$ cific warm pool during the TOGA COARE and to explain their connection with the dynamics of the nearsurface layer of the ocean. The paper is organized as follows. Section 2 gives a brief information about the instrumentation and techniques. Section 3 describes observations of the sharp frontal interfaces in the western Pacific warm pool. Section 4 gives examples of vertical structure near the frontal interfaces. In section 5, physics of the observed frontal structures is considered, including comparison with laboratory experiments and a theoretical model. In section 6, observations and theory are discussed, and the last section (section 7) contains conclusions.

\section{Apparatus and techniques}

High-resolution probes were mounted on the bow of the R/V Moana Wave (University of Hawaii at 
TABLE 1. Main technical characteristics of the ECTP probe during cruises on R/V Moana Wave.

\begin{tabular}{|c|c|c|c|}
\hline Parameter & $\begin{array}{c}\text { COARE IOP-3 } \\
\text { and EQ-2 } \\
\text { (ECTP \#A283) }\end{array}$ & $\begin{array}{l}\text { COARE transit } \\
\text { (ECTP \#1) }\end{array}$ & $\begin{array}{c}\text { COARE EQ-3 } \\
\text { (ECTP \#1) }\end{array}$ \\
\hline \multicolumn{4}{|c|}{ Temperature } \\
\hline Range $\left({ }^{\circ} \mathrm{C}\right)$ & $-2-35$ & $14-34$ & $14-34$ \\
\hline Accuracy $\left({ }^{\circ} \mathrm{C}\right)$ & 0.1 & 0.1 & 0.1 \\
\hline Stability during $8 \mathrm{~h}\left({ }^{\circ} \mathrm{C}\right)$ & $<0.01$ & $<0.01$ & $<0.01$ \\
\hline Digital resolution $\left({ }^{\circ} \mathrm{C}\right)$ & 0.003 & 0.005 & 0.005 \\
\hline Response time of primary sensor (ms) & 35 & 35 & 35 \\
\hline \multicolumn{4}{|c|}{ Fluctuation temperature } \\
\hline Range $\left({ }^{\circ} \mathrm{C}\right)$ & \pm 2.5 & \pm 1.0 & $\pm 1.0( \pm 2.0$ from 11 Apr 94$)$ \\
\hline Noise level $\left({ }^{\circ} \mathrm{C}\right)$ & 0.001 & 0.001 & 0.001 \\
\hline Digital resolution $\left({ }^{\circ} \mathrm{C}\right)$ & 0.0012 & 0.0005 & 0.0005 (0.001 from 11 Apr 94) \\
\hline Frequency range $(\mathrm{Hz})$ & $0.012-50$ & $0.012-50$ & $0.012-50$ \\
\hline \multicolumn{4}{|c|}{ Conductivity } \\
\hline Range $(\mathrm{S} / \mathrm{m})$ & $1.5-7.0$ & $3.1-6.1$ & $3.1-6.1$ \\
\hline Accuracy $(\mathrm{S} / \mathrm{m})$ & 0.01 & 0.01 & 0.01 \\
\hline Stability during $8 \mathrm{~h}\left(\mathrm{~S} \mathrm{~m}^{-1}\right)$ & $<0.001$ & $<0.001$ & $<0.001$ \\
\hline Digital resolution $\left(\mathrm{S} \mathrm{m}^{-1}\right)$ & 0.00056 & 0.0012 & 0.0012 \\
\hline Space resolution $(\mathrm{m})$ & 0.1 & 0.1 & 0.1 \\
\hline \multicolumn{4}{|c|}{ Fluctuation conductivity } \\
\hline Range $\left(\mathrm{S} \mathrm{m}^{-1}\right)$ & \pm 0.25 & \pm 0.1 & $\pm 0.1( \pm 0.2$ from 11 Apr 94$)$ \\
\hline Digital resolution $\left(\mathrm{S} \mathrm{m}^{-1}\right)$ & 0.00012 & 0.00005 & $0.00005(0.0001$ from 11 Apr 94) \\
\hline Noise level of output voltage $\left(\mathrm{S} \mathrm{m}^{-1}\right)$ & 0.0001 & 0.0001 & 0.0001 \\
\hline Frequency range $(\mathrm{Hz})$ & $0.012-50$ & $0.012-50$ & $0.012-50$ \\
\hline \multicolumn{4}{|c|}{ Pressure } \\
\hline Range (dbar) & $0-25$ & $0-25$ & $0-25$ \\
\hline Accuracy (dbar) & $0.1^{*}$ & $0.1^{*}$ & $0.1 *$ \\
\hline Digital resolution (dbar) & 0.01 & 0.01 & 0.01 \\
\hline
\end{tabular}

*After correction of temperature dependence.

Manoa) at $\sim 1.7-\mathrm{m}$ depth using a special frame (Volkov et al. 1988; Soloviev 1990; Soloviev et al. 1995). When the ship moved forward through the water faster than $2 \mathrm{~m} \mathrm{~s}^{-1}$, the probes were in an undisturbed region. The instrument package installed on the bow of the R/V Moana Wave included an electrical conductivity-temperature-pressure probe (ECTP) and an electromagnetic velocity and acceleration probe (EMVA). The ECTP probe contained a copper-wire temperature sensor, an inductive conductivity cell, and a pressure sensor of the strain-gauge type. Table 1 gives the main technical characteristics of the ECTP probes used during COARE (the EMVA data are not used in this paper).

Temperature-salinity measurements were made simultaneously by the thermosalinograph system (SeaBird Electronics CTD SBE-21) of the R/V Moana Wave (Shinoda et al. 1995), pumping water from the bow intake at 3-m depth. During travel via the thermosalinograph system pipeline, the water temperature changed slightly $\left(\sim 0.02^{\circ} \mathrm{C}\right)$. To control this heating process, an additional thermistor was installed at the bow intake at $\sim 3 \mathrm{~m}$ depth. For the Moana Wave COARE EQ-3 cruise (30 days), the bow sensor temperature and salinity within the pressure range of $2.8-3.2$ dbar were averaged over 10-min time intervals and compared with the corresponding 10-min averages of the thermosalinograph temperature and salinity. The results of this intercomparison are the following. An rms difference of 0.014 psu and a slow mean difference drift from -0.013 to 0.001 psu between the bow and thermosalinograph salinity were seen during the EQ-3 cruise. The salinity difference drift can be partially explained by a drift of the ECTP temperature sensor. During EQ-3, the mean temperature difference between the bow probe and thermosalinograph thermistor at the 3-m intake drifted from $0.034^{\circ}$ to $0.057^{\circ} \mathrm{C}$. The corresponding rms difference between the bow temperature probe and the thermosalinograph thermistor at the $3-\mathrm{m}$ intake was equal to $0.012^{\circ} \mathrm{C}$.

For the data acquisition, we used two sampling rates: 40 and $400 \mathrm{~Hz}$. Surfacing of the probes and bubble patches disturb the measurement of conductivity. Bubbles may also disturb the temperature measurements (Farmer and Gemmrich 1996). An algorithm has been developed that automatically detects and removes surfacing and air bubble areas from the signals. To match the phase shift and response time of the temperature and conductivity sensors at calculation of salinity, we used techniques of Fozdar et al. (1985). Finally, the dataset was filtered and decimated to $8-\mathrm{Hz}$ sampling rate. More details about the apparatus, techniques, and software can be found in Soloviev et al. (1995). 


\section{Horizontal structure}

Measurements were made in February 1993 (COARE IOP-3 cruise of R/V Moana Wave), in March 1993 (COARE EQ-2 cruise of R/V Moana Wave), and in March-May 1994 (COARE Transit and EQ-3 cruises of Moana Wave). An example of the vertical thermohaline structure of the surface layer of the ocean in the western Pacific warm pool when the sharp frontal interfaces were observed is shown in Fig. 1. During the measurements we intersected many frontal interfaces. Figure 2 shows a record during 13 hours of steaming the ship. The temperature $(T)$, salinity $(S)$, and density $\left(\sigma_{t}\right)$ series reveal a quasiperiodical structure of about $10-60-\mathrm{km}$ wavelength. A feature of this structure is its strong asymmetry. A gradual rise of density is followed by its abrupt decrease. This quasiperiodical structure is observed on the background of the mean horizontal density gradient of about $0.001 \mathrm{~kg} \mathrm{~m}^{-3} \mathrm{~km}^{-1}$.

Some of the frontal interfaces are very localized in space. To detect such structures, we employed a special algorithm described in appendix A. During Moana Wave EQ-3 cruise (30 days), 132 sharp frontal interfaces are detected by this algorithm on a $\sigma_{t}$ dataset from the bow sensors. For the record shown in Fig. 2, the algorithm applied to the $\sigma_{t}$ signal detected 17 sharp frontal interfaces. They are marked by asterisks. Figure 3 shows these sharp frontal interfaces in more detail. They are narrow-sometimes only a few meters. In the scaling used in Fig. 3, some of them look like a discontinuity or "wall." A corresponding record of temperature and salinity from the thermosalinograph, which measured water drawn from 3-m depth, is also shown in Fig. 3. The thermosalinograph reveals the same frontal interfaces both in temperature and salinity, but delayed and smoothed within an approximately 100-m length scale because of the slower response of the thermosalinograph system.

The detailed picture (Fig. 4) of the narrowest interface from this section shows that the real width of this interface is only $\sim 1.5 \mathrm{~m}$. The absolute values of the horizontal temperature, salinity, and density gradients within this interface are $137.8^{\circ} \mathrm{C} \mathrm{km}^{-1}, 125.8 \mathrm{psu} \mathrm{km} \mathrm{km}^{-1}$, and $47.96 \mathrm{~kg} \mathrm{~m}^{-3} \mathrm{~km}^{-1}$.

A special experiment in which the ship moved on a "snake" trajectory was performed to determine the orientation of such structures to the wind direction (Fig. 5). The sharp frontal interface was oriented approximately $45^{\circ}-80^{\circ}$ to the wind direction. A reciprocal course was run at slower ship speed in order to obtain data at higher resolution while crossing the front. The actual record of $P, T, S$, and $\sigma_{t}$ and ship speed measurements during the maneuver plotted in Fig. 5 is shown in Fig. 6. The $T$ and $S$ records during the fifth intersection of the frontal interface (Fig. 6) were smoother because the ship moved almost along the front (see Fig. 5). Figure 7 shows the intersections of the frontal interface on a detailed distance scale.
Intersections 2, 4, and 6 are plotted in the inverse direction because of the reciprocal course of the ship at these intersections. For intersections 5, 6, and 7 the horizontal scale is multiplied by $0.15,0.5$, and 0.5 respectively to correct for an oblique angle of intersection with the frontal interface. A feature of this interface is that it is seen on the $\sigma_{t}$ record only at intersections 1, 2, and 3. For the intersections 4, 5, 6 , and 7 the frontal interface is almost compensated in the density field but is still seen on the $T$ and $S$ records. The interfaces shown in Fig. 7 are of about one order of value thicker than those shown in Fig. 3. We ascribe this difference to the wind stress direction opposing the buoyant spreading of the front in the former case (Fig. 7). The sharp frontal interfaces presented in Fig. 3 were recorded when the wind stress had a component in the same direction as the buoyant spreading of the front (first seven segments) or was very small (last five segments).

Orientation of the sharp frontal interfaces relative to the wind direction has been analyzed for all 30 days of observations in the EQ-3 cruise. In Fig. 8a, the density difference across the sharp frontal interface $\Delta \sigma_{t}$ is plotted as a function of the ship-to-wind direction $\Theta$. At the intersection of the sharp frontal interface we do not know the intersection angle. The measured maximum density gradient within the frontal interface is proportional to $\cos \alpha$, where $\alpha$ is the relative angle between the ship's direction and a normal line to the front $\left(-90^{\circ}\right.$ $<\alpha<90^{\circ}$ ). This is because the apparent width of the frontal interface is equal to $l=l_{0} / \cos \alpha$, where $l_{0}$ is the actual width of the interface. The probability density of the frontal interface detection by the algorithm described in appendix $\mathrm{A}$ is therefore proportional to $\cos \alpha$, being maximum at $\alpha=0^{\circ}$. For the detected interfaces, the intersection angle $\alpha$ is thus randomly scattered near $\alpha$ $=0^{\circ}$ with a mathematical expectation $\langle\alpha\rangle=0^{\circ}$, where angle brackets denote the averaging operator. Averaging over a large number of cases will result in the following relation, $\langle\Theta\rangle \approx\langle a\rangle$.

Corresponding values of the density difference, $\left\langle\Delta \sigma_{t}\right\rangle$, averaged on $\Theta$ within $\pm 30^{\circ}$ are given in Fig. $8 \mathrm{~b}$. This plot shows a spatial anisotropy of the sharp frontal interfaces with respect to the wind direction. According to Fig. 8a, most of the sharp frontal interfaces were detected on $\sigma_{t}$ in cases when the wind speed was along the direction of buoyant spreading of the front (see examples in Fig. 3). When the wind stress was in the opposite direction relative to the buoyant spreading, the observed sharp frontal interfaces were mainly compensated in the density field (see examples in Fig. 7).

The density difference across the sharp frontal interface $\Delta \sigma_{t}$ is plotted in Fig. $8 \mathrm{c}$ as function of the wind speed magnitude. The averaged plot (Fig. 8d) does not reveal statistically significant wind magnitude dependence. Note that the algorithm described in appendix A is aimed for detection of the sharpest frontal interfaces. 

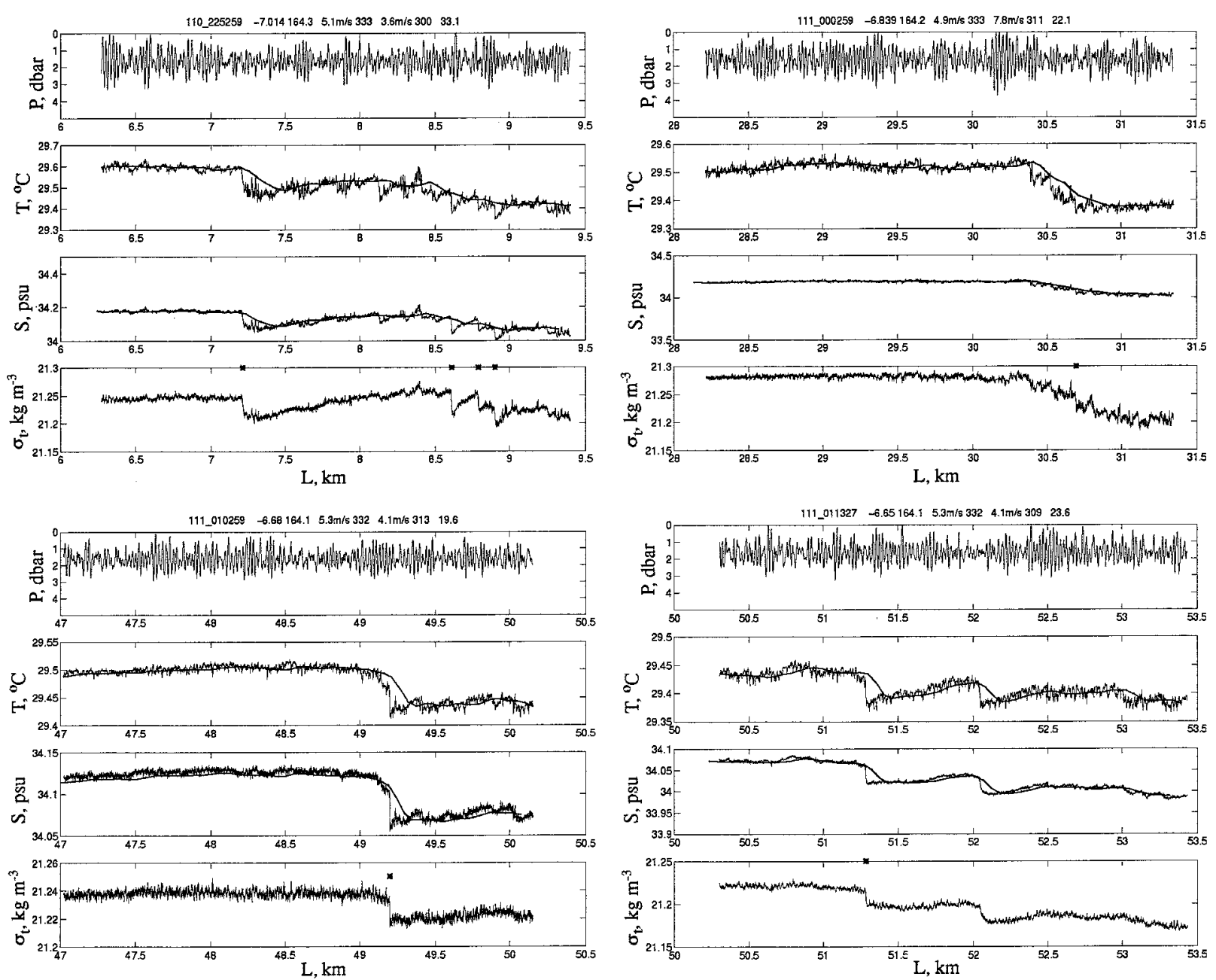

FIG. 3. Ten-minute segments of pressure, temperature, salinity, and density showing intersections with the sharp frontal interfaces. Corresponding records of temperature (bow thermistor at 3-m intake) and salinity from the thermosalinograph system are shown by smooth bold lines. Position of the segments with respect to the graphs shown in Fig. 2 can be identified using the distance scale. Title of each 10-min segment plot contains the file name, latitude, longitude, ship speed, ship direction, wind speed, wind direction, and relative angle of the ship to wind direction. The file name consists of Julian day and the UTC time of the file beginning.

The wind magnitude dependence would presumably become appreciable for smoother interfaces.

\section{Vertical structure}

Soloviev and Zatsepin (1992) reported a connection of the sharp frontal interfaces with the presence of nearsurface thermohaline anomalies within the upper-ocean mixed layer. In the western Pacific warm pool, the upper layer of the ocean is typically weakly stratified (Fig. 1). During our observations in the Moana Wave COARE EQ-3 cruise, systematic measurements of the vertical structure near the sharp frontal interfaces were not performed. The frontal interfaces were localized in space and the moments of their intersection were unknown in advance. Sudden changes of the ship's schedule to measure the vertical profiles across the frontal interfaces would have substantially interfered with other projects.
Bow measurements were also performed from the R/V Wecoma (Paulson and Largerloef 1993) simultaneously with the SEASOAR surveys (O'Malley et al. 1994) during the TOGA COARE. Figure 9 gives an example of the sharp frontal interface and of the spatial structure of the surface layer of the ocean near this interface as observed in Wecoma COARE IOP-2 leg. The Wecoma data suggest that the appearance of the sharp frontal interfaces is connected to the thermohaline anomalies in the upper mixed layer. In Fig. 9, the sharp frontal interface at $45.6 \mathrm{~km}$ corresponds to the right edge of the near-surface density depression anomaly. The core of this density anomaly is located in the upper 5$15-\mathrm{m}$ layer of the ocean and is formed by a series of strong rain events. On the contour plot in Fig. 9, the near-surface density structure has some similarity to the gravity current spreading from the left to the right part of this figure. 

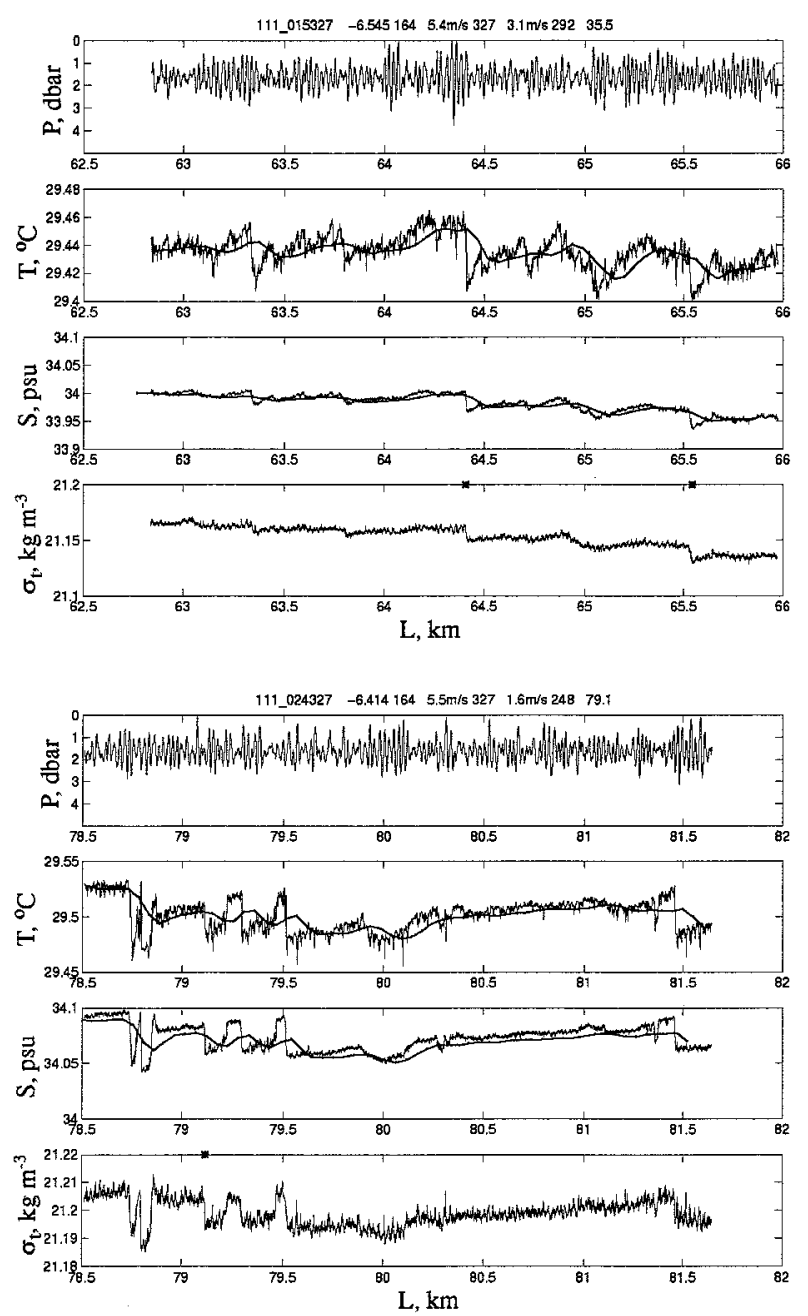

FIG. 3. (Continued)

\section{Physical considerations}

\section{a. Possible generation mechanisms}

The present attempt to explain the occurrence of the sharp frontal interfaces in the near-surface layer of the ocean is based on the available data, which were mainly obtained during the TOGA COARE field study. The experimental facts can be briefly summarized as follows. The observations reveal repeating frontal interfaces of width $1-100 \mathrm{~m}$, which are apparently connected to the thermohaline anomalies within the upper mixed layer. The sharp frontal interfaces demonstrate a spatial anisotropy with respect to the wind direction. A strong asymmetry of $0.2-60-\mathrm{km}$ scale horizontal structures associated with the appearance of these interfaces suggests that this is some kind of nonlinear process similar to that forming the internal surge or bore.

Relatively small depth of the near-surface anomalies is favorable for development of nonlinear internal waves. To explain the observations we will therefore follow a hypothesis that the sharp frontal interfaces in
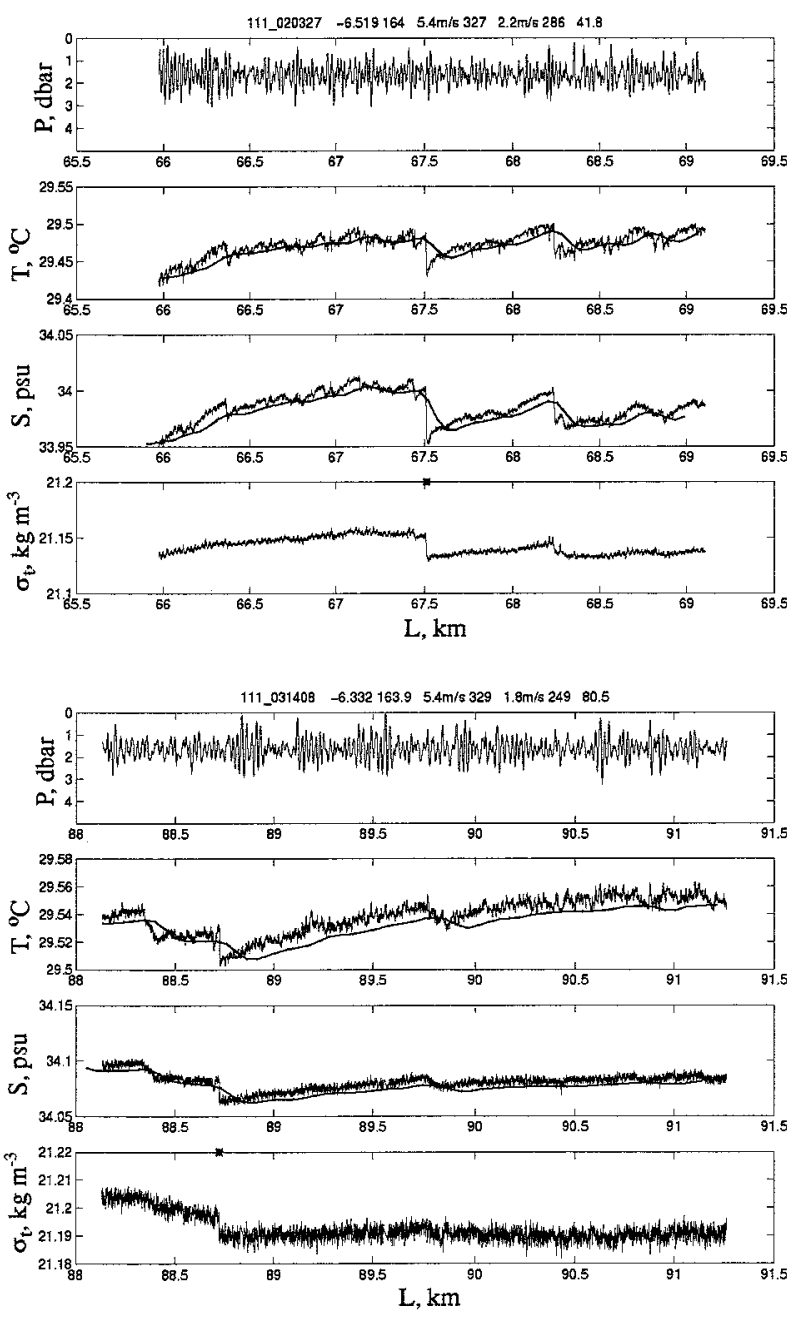

the warm pool area may occur as a result of nonlinear buoyant adjustment of the stably stratified near-surface layer of the ocean to external forcing. The external forcing may include the variable buoyancy flux and wind stress at the ocean-air interface, tidal motions, and so forth. This is a nonlinear problem and its faithful solution in the framework of the hydrodynamics equations is not feasible now. An analysis described below is based on results of the laboratory studies of the buoyancy-driven currents and on a shallow-water approximation of the problem.

According to Simpson (1987), any density depression anomaly in the upper water layer tends to spread in the horizontal direction. The leading edge of a gravity current typically forms a sharp dividing line. A characteristic 'head' that is deeper than the following flow is usually formed near the front. A passage of a gravity current along a boundary through a uniformly stratified medium can generate several different modes of the internal waves. According to the laboratory observation (see Simpson 1987), “... These waves affected the 

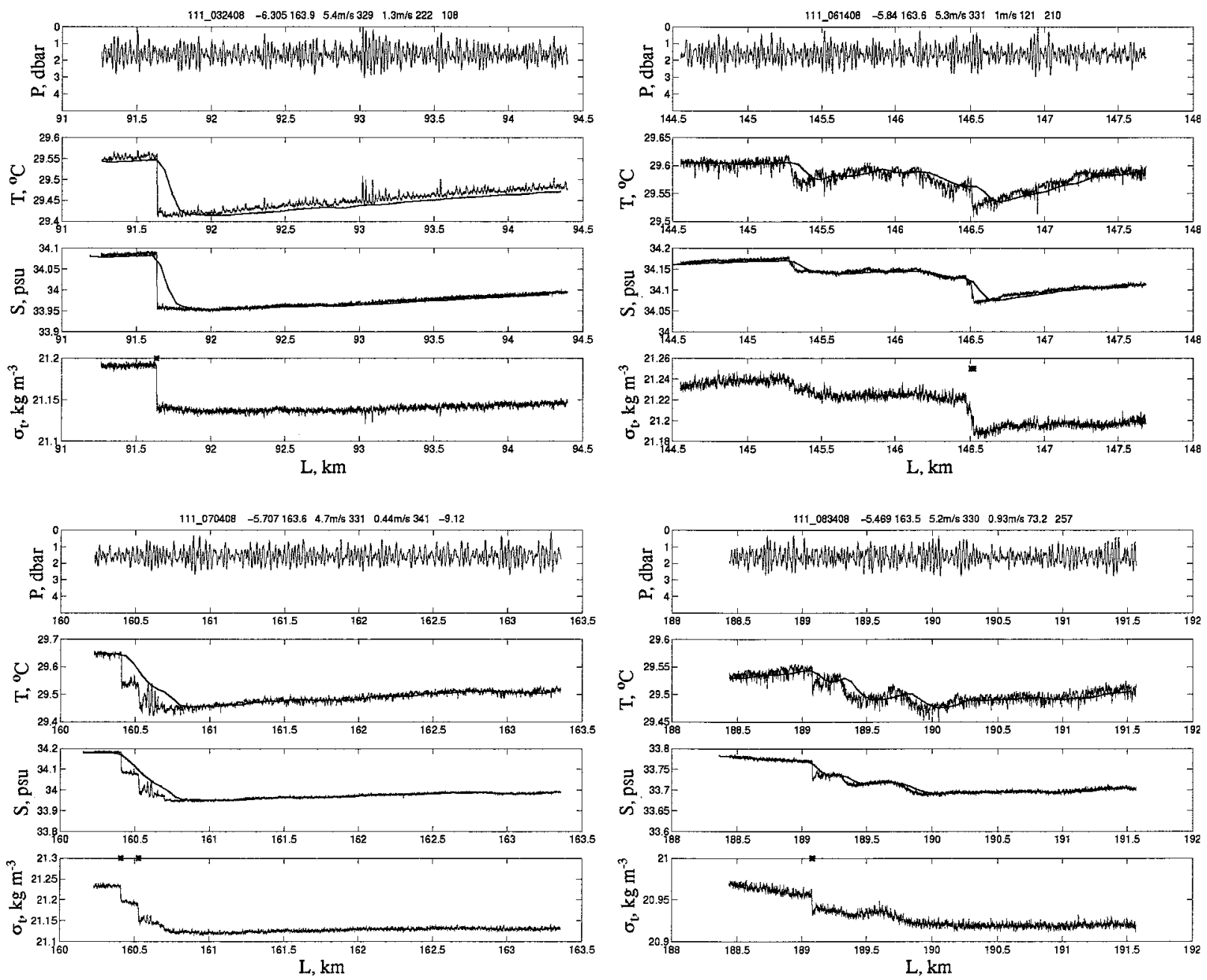

FIG. 3. (Continued)
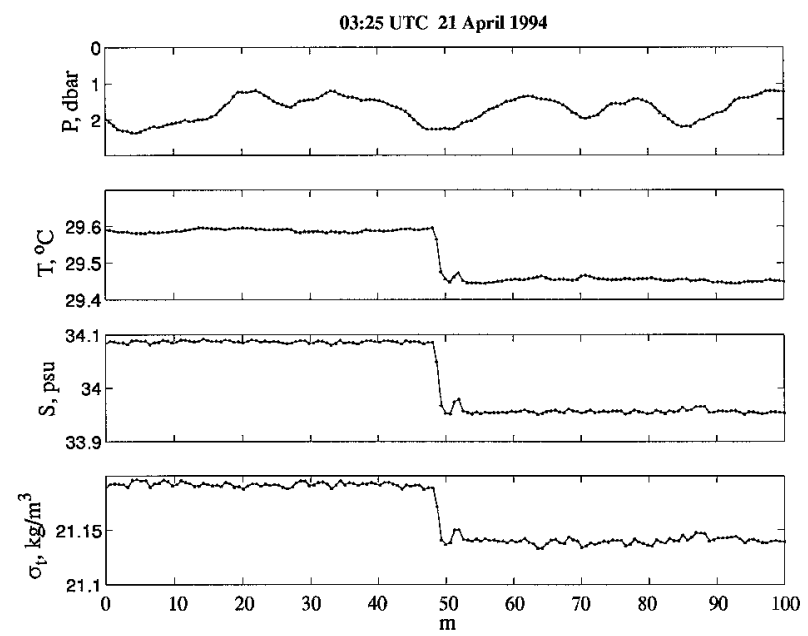

FIG. 4. Structure of the frontal interface at $91.6 \mathrm{~km}$ (see section shown in Figs. 2 and 3) in more detail. Horizontal scale is in meters.

form of the gravity current behind the head in a rhythmical manner. The fluid in the original head was cut off from the flow, which formed a second head. The process was repeated and later a third new front appeared ...." However, the striking effects could be observed only when the Froude number,

$$
\operatorname{Fr}=\frac{U}{N H}<\frac{1}{\pi}
$$

(where $U$ is the speed of the gravity current and $N$ is the Brunt-Väisälä frequency of stratified surroundings) and the fractional depth of the gravity current was less than 0.2 of the total depth $H$. In the equatorial region, the maximum spatial scale of the buoyancy-driven anomalies is restricted by the baroclinic equatorial Rossby radius (Moore and Philander 1977). The baroclinic equatorial Rossby radius for internal perturbations

$$
R_{\beta}=\left(\frac{c}{2 \beta}\right)^{1 / 2}
$$




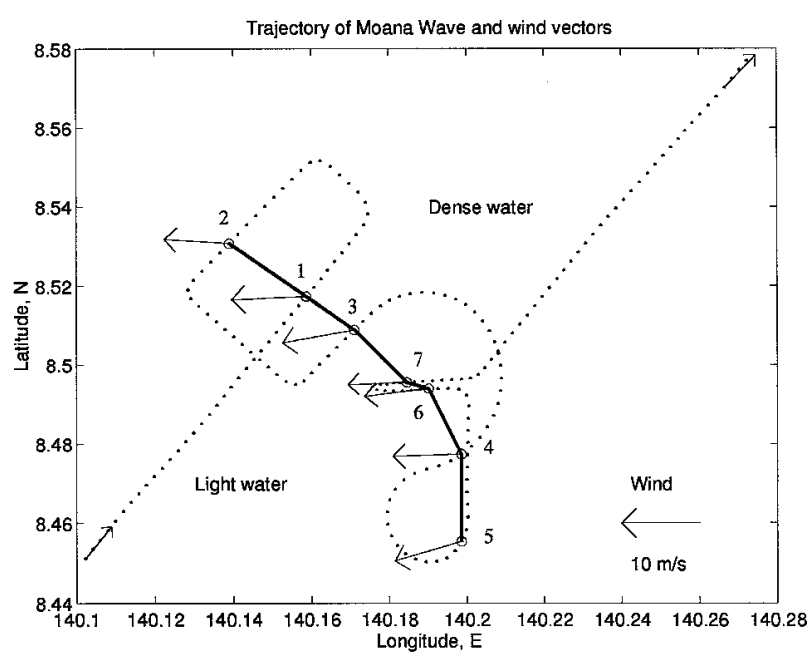

FIG. 5. "Snake" trajectory of the ship and places of intersection of a sharp frontal interface. Trajectory of the ship is shown by points; the time interval between the points is equal to $1 \mathrm{~min}$. The frontal interface being determined by the points of its intersection by the ship (circles numbered from 1 through 7 ) is shown by a solid line. Appropriate values of the wind vectors from the ship's measurements are also shown. where $\beta=(\partial f / \partial y)_{\phi=0}=2.3 \times 10^{-11} \mathrm{~m}^{-1} \mathrm{~s}^{-1}, f$ is the Coriolis parameter, and $c$ is the phase speed of internal perturbations. At $c=0.1-0.4 \mathrm{~m} \mathrm{~s}^{-1}$ (typical for the nearsurface stratification above the barrier layer), $R_{\beta} \approx 50-$ $100 \mathrm{~km}$, which corresponds to the maximum horizontal distance between the sharp frontal interfaces that we observed in the equatorial warm pool.

In Fig. 9, the sharp frontal interface observed at 45.6 $\mathrm{km}$ may be associated with the leading edge of the density-driven current. The form of the $\sigma_{t}=21.6 \mathrm{~kg} \mathrm{~m}^{-3}$ isopycnic surface between 25 and $50 \mathrm{~km}$ looks like a contour of the head of the gravity current. However, the ADCP data (available only for depths $>20 \mathrm{~m}$ ) indicate that this feature had a cyclonic vorticity and might be caused by an inertial spindown of the eastward equatorial jet (Lukas and Hacker 1995) rather than by the buoyancy force by itself.

Figure 10 shows the same east to west Wecoma section being repeated in about 32 hours. The bow sensors data indicated that the sharp frontal interface moved to the east $\sim 9 \mathrm{~km}$, which corresponded to a speed $U \sim 8$ $\mathrm{cm} \mathrm{s}^{-1}$. This is, however, a crude estimate because the "background" current speed in the upper $20 \mathrm{~m}$ of the ocean is unknown. Lateral variability might therefore have a role to play in creating the differences between the contour plots shown in Figs. 9 and 10. A considerable difference in the volume of water contained above
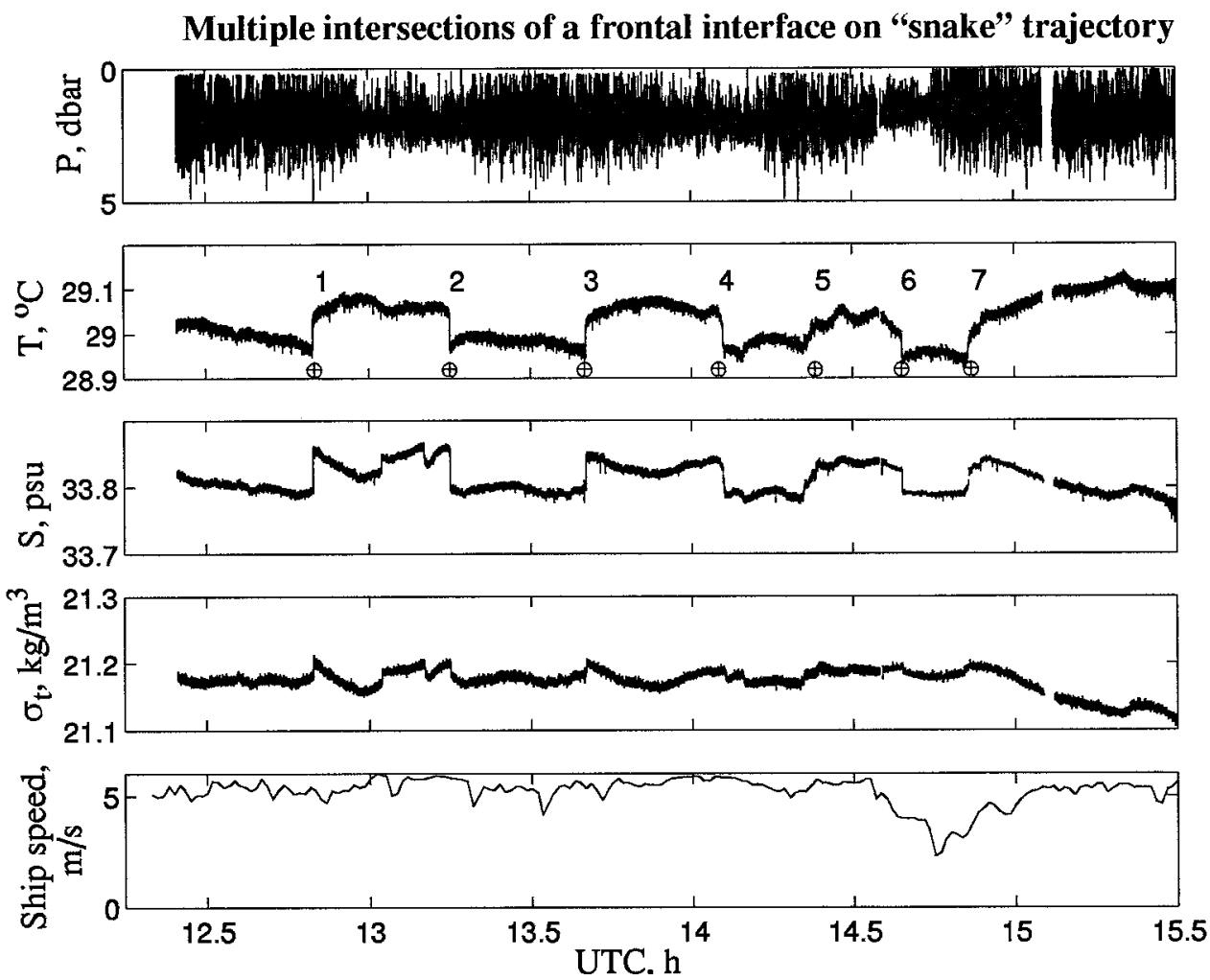

FIG. 6. Records of pressure, temperature, salinity, density, and ship speed during the "snake" trajectory of the ship shown in Fig. 5. Intersections with the frontal interface are shown by crossed circles below the temperature record, the intersections are numbered 1-7. 
the $\sigma_{t}=21.6 \mathrm{~kg} \mathrm{~m}^{-3}$ surface between the plots shown in Figs. 9 and 10 is mainly because of a 5-m offset of the SEASOAR pressure sensor that occurred in the latter section because of technical problems.

The density contour plot in Fig. 10 shows that the original head of the gravity current could be cut off from the flow (see the near-surface feature between 40 and $50 \mathrm{~km}$ ). This is in accord with the laboratory studies discussed above. The fractional depth of the rain-formed density depression (compared to mixed layer depth $H$ $=80 \mathrm{~m})$ is $\sim 0.06<0.2$. An estimate of the Froude number Fr $\sim 0.3$ corresponds to criteria (1) (background buoyancy frequency $N \approx 3.3 \times 10^{-3} \mathrm{~s}^{-1}$ ).

\section{b. Internal bore model}

The structural form of the sharp frontal interfaces observed in the warm pool area has some similarity with that of the internal surge or internal bore previously observed in long stably stratified lakes (Thorpe 1971; Thorpe et al. 1972; Hunkins and Fliegel 1973; Farmer 1978). A common feature is that the gradual rise of the density is followed by the abrupt decrease in the relatively narrow frontal region. The surgelike and borelike structures are also often observed in straits (Ziegenbein 1969; Kinder 1984) and in shallow coastal waters (Halpern 1971; Lee and Beardsley 1974; Winant 1974; Haury et al. 1979; Osborne and Burch 1980; Alpers and Salusti 1983; Apel et al. 1985), associated with topographic wave generating regions. The principal difference in our observations of such structures is that they relate to the deep water region with depths exceeding $2000 \mathrm{~m}$.

The dynamics of the near-surface stratified layer of the ocean can be explored using the shallow water approximation (Long 1972; Whitham 1974; Farmer 1978; Barenblatt and Shapiro 1984). Evolution of an initially smooth perturbation into an asymmetrical structure is described in the framework of shallow-water theory similar to the analysis of Farmer (1978) for long stably stratified lakes. The generation of the borelike structure can be explored using a model based on the equation of Korteweg-de Vries-Burgers type including both dissipation and dispersion (appendix B). The model predicts evolution of an initially smooth disturbance of the near-surface pycnocline into a shock-wave structure. A Reynolds-type number is the criterion of transition from wave train solution to dissipative shock-wave structure (Barenblatt and Shapiro 1984)

$$
\operatorname{Re}_{*}=\frac{h\left(g^{\prime} h\right)^{1 / 2}}{\nu_{e}} .
$$

For $\mathrm{Re}_{*}>\mathrm{Re}_{\text {cr }}$ the solution is expected to be of a wavelike nature (and finally evolve into a series of solitons) and of turbulent nature (and finally evolve into a dissipative shock-wave structure) for $\mathrm{Re}_{*}<\mathrm{Re}_{\mathrm{cr}}$, where $\mathrm{Re}_{\text {cr }} \approx 2.74$ (see appendix $\mathrm{B}$ ).

The numerator in (2) represents the phase speed of
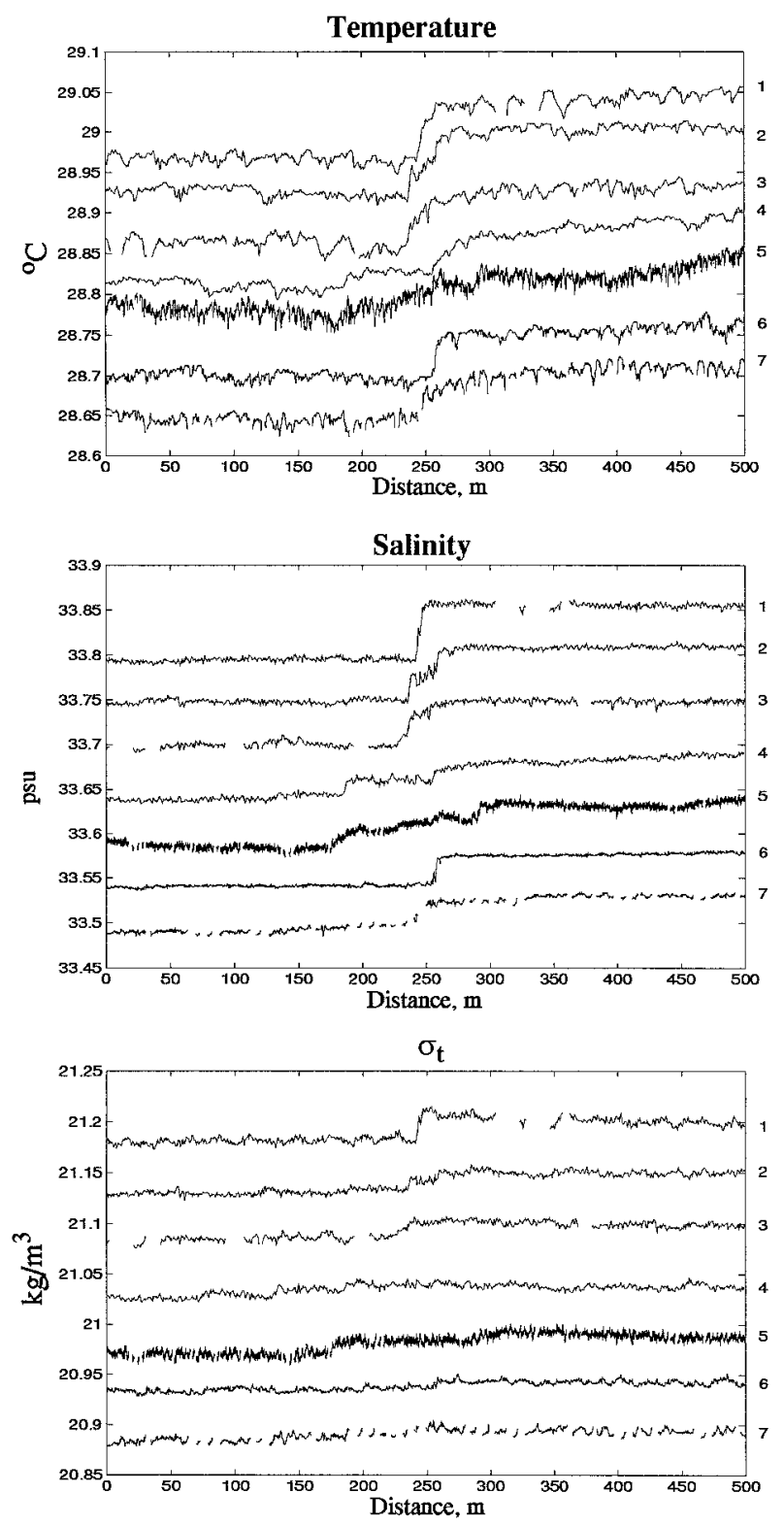

FIG. 7. Microstructure of the sharp frontal interface shown on Fig. 5. Blank spaces on $\mathrm{S}$ and $\sigma_{t}$ profiles correspond to surfacing of the probes due to ship pitching.

the internal perturbation times the depth of the stratified layer. It decreases when stratification is relatively weaker and the layer depth is smaller. For a given value of the effective viscosity $\nu_{e}$ for a strong and deep thermocline (e.g., the seasonal thermocline) a soliton-type response to external forcing is expected to be more typical. On the other hand, the response of the upper ocean to external forcing in the form of a turbulent internal bore $\left(\mathrm{Re}_{*}<\mathrm{Re}_{\mathrm{cr}}\right)$ is more probable for a weakly stratified mixed layer.

The internal bore model described in appendix B requires an initial long-wave disturbance of the near-sur- 

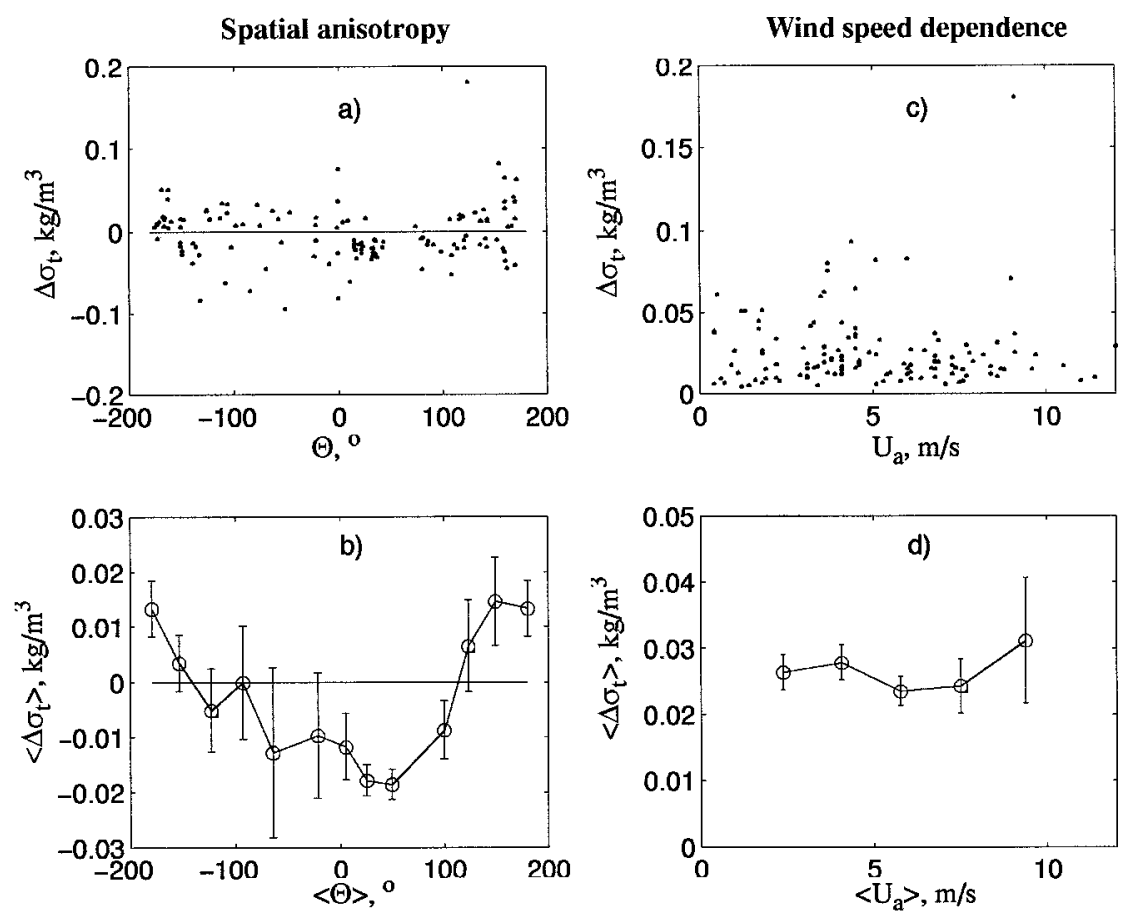

FIG. 8. (a) Dependence of the density difference $\Delta \sigma_{t}$ across the sharp frontal interfaces (detected in the EQ-3 cruise using the algorithm described in appendix A) on relative ship-to-wind angle $\Theta$. (b) Same as graph (a) but averaged on $\Theta$ within $\pm 30^{\circ}$ interval. (c) Dependence of $\Delta \sigma_{t}$ on wind speed magnitude $U_{a}$. (d) Same as graph (c) but averaged on $U_{a}$ within $\pm 2 \mathrm{~m} \mathrm{~s}^{-1}$ interval. The vertical bars represent one standard error confidence limits.

face pycnocline. The variable buoyancy and momentum flux at the air-sea interface and the inertial or tidal motions could be sources of long-wave perturbations for the weakly stratified mixed layer. Picaut et al. (1995) found strong surface-to-bottom internal tides, mostly semidiurnal in the TOGA COARE domain. The intensity of the tidal waves depended on the bottom topography. They appeared most energetic in the thermocline. Pinkel et al. (1994) observed a large amplitude soliton in the thermocline in the TOGA COARE domain, associated with large baroclinic tides. It is, however, not clear at this point how the weakly stratified mixed layer responds to the tidal forcing.

One of the problems of the analysis based on Whitham's (1974) model is that the effective viscosity, which can be obtained by parameterizing it via the mean shear flow, is about 10 times smaller than necessary to achieve the critical value of $\mathrm{Re}_{*}$. However, taking into account additional convective instability at the frontal interface resulting from its interaction with the wind stress resolves the problem. Further analysis (section 5c) will show that for a shallow pycnocline the direction of wind stress relative to the frontal interface is important.

\section{c. Wind stress effects}

An important aspect of the buoyancy-driven currents is that they are very sensitive to any opposing or fol- lowing flow in the environment (Simpson 1987). The wind stress may therefore substantially control the advance of the buoyancy current advancing along the ocean surface; the direction of the wind stress with respect to evolution of the frontal interface is therefore important. Figure 11 illustrates the two situations in the near-surface layer reconstructed on the basis of laboratory modeling of the gravity currents (Simpson 1987): the wind stress is directed against the direction of propagation of the frontal interface (a) and with it (b).

When the surface stress has a component in the direction of the gravity current propagation (Fig. 11b), the front has the same structure of the ambient flow as in an arrested wedge (Simpson 1987), and entrainment ceases. This corresponds to our observations of the sharp frontal interfaces when the wind stress was along the direction of the buoyant spreading of the front (i.e., when $\theta>90^{\circ}$ or $\theta<-90^{\circ}$, where $\theta$ is the wind direction with respect to the direction of buoyant spreading of the front). Examples can be seen in Figs. 3 and 4.

In the opposite case (Fig. 11a), when the surface wind stress has a component against the direction of the gravity current (for the frontal interface this occurs at angles $-90^{\circ}$ $>\theta>90^{\circ}$ ), the entrainment flux may substantially increase. Most of this entrainment occurs at the tail part of the gravity current head destabilized by Kelvin-Helmholztype instability. A so-called nose (foremost point of gravity current) is formed near the ocean surface above which 

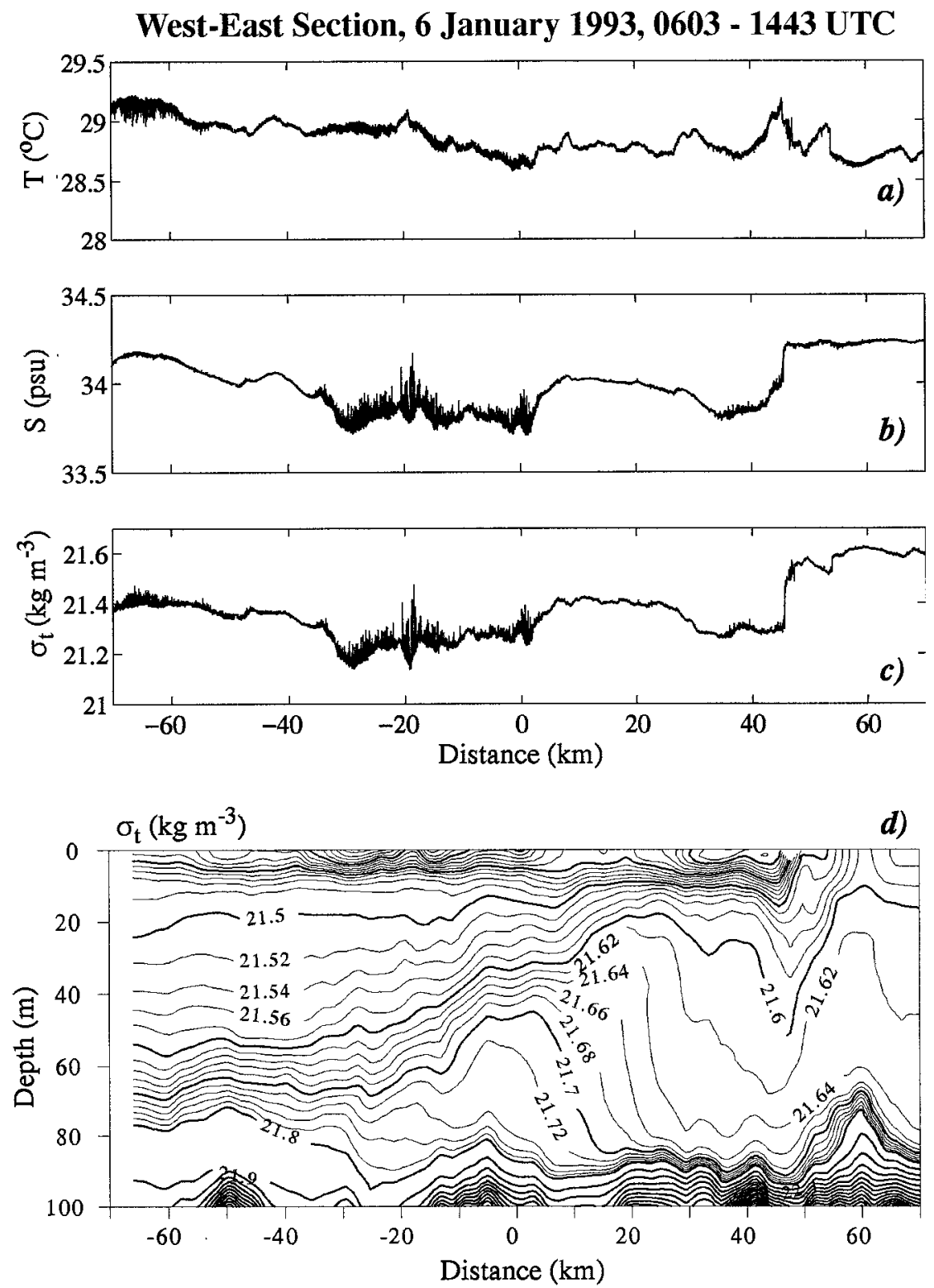

FIG. 9. Intersection of sharp frontal interface in Wecoma COARE IOP-2 cruise during the east-west section on 6 January 1993 (ship direction $90^{\circ}$ ). Wind speed at $45.6 \mathrm{~km}$ (intersection of sharp frontal interface) is $0.8 \mathrm{~m} \mathrm{~s}^{-1}$, wind direction $87^{\circ}$. Horizontal distance is calculated with respect to the point with coordinates $1^{\circ} 50^{\prime} \mathrm{S}, 156^{\circ} 06^{\prime} \mathrm{E}$. Three upper subplots (a-c) are from Paulson's (see Paulson and Largerloef 1993) bow sensors mounted at 2-m depth; (d) density contour plot is calculated from SEASOAR survey. For contour plot, step in density is $0.1 \mathrm{~kg}$ $\mathrm{m}^{-3}$ for $21.10 \mathrm{~kg} \mathrm{~m}^{-3}<\sigma_{t}<21.8 . \mathrm{kg} \mathrm{m}^{-3}$ and $0.02 \mathrm{~kg} \mathrm{~m}^{-3}$ for $\sigma_{t}>21.8 \mathrm{~kg} \mathrm{~m}^{-3}$.

ambient, more dense water penetrates into the gravity current. The more dense water flowing above the nose of the head results in convective overturning. The flux of the more dense water between the surface and the nose is, however, only $O\left(10^{-1}\right)$ of the light water mixing rate at the tail part of the head of the gravity current (Simpson and Britter 1979). The convectively enhanced mixing provides conditions for development of the turbulent bore. When the turbulent bore develops, the energy for the tur- bulent entrainment via the frontal interface is, however, mainly extracted from the gravity current. The gravity current is driven by the horizontal buoyancy gradient and has a much larger mechanical energy compared to the energy of the convective overturning within the frontal interface. The entrainment flux at the tail part of the gravity current head can achieve a relatively large value, estimated by Simpson (1987) to be equal to 0.15 times the mass flux of the gravity current itself. 

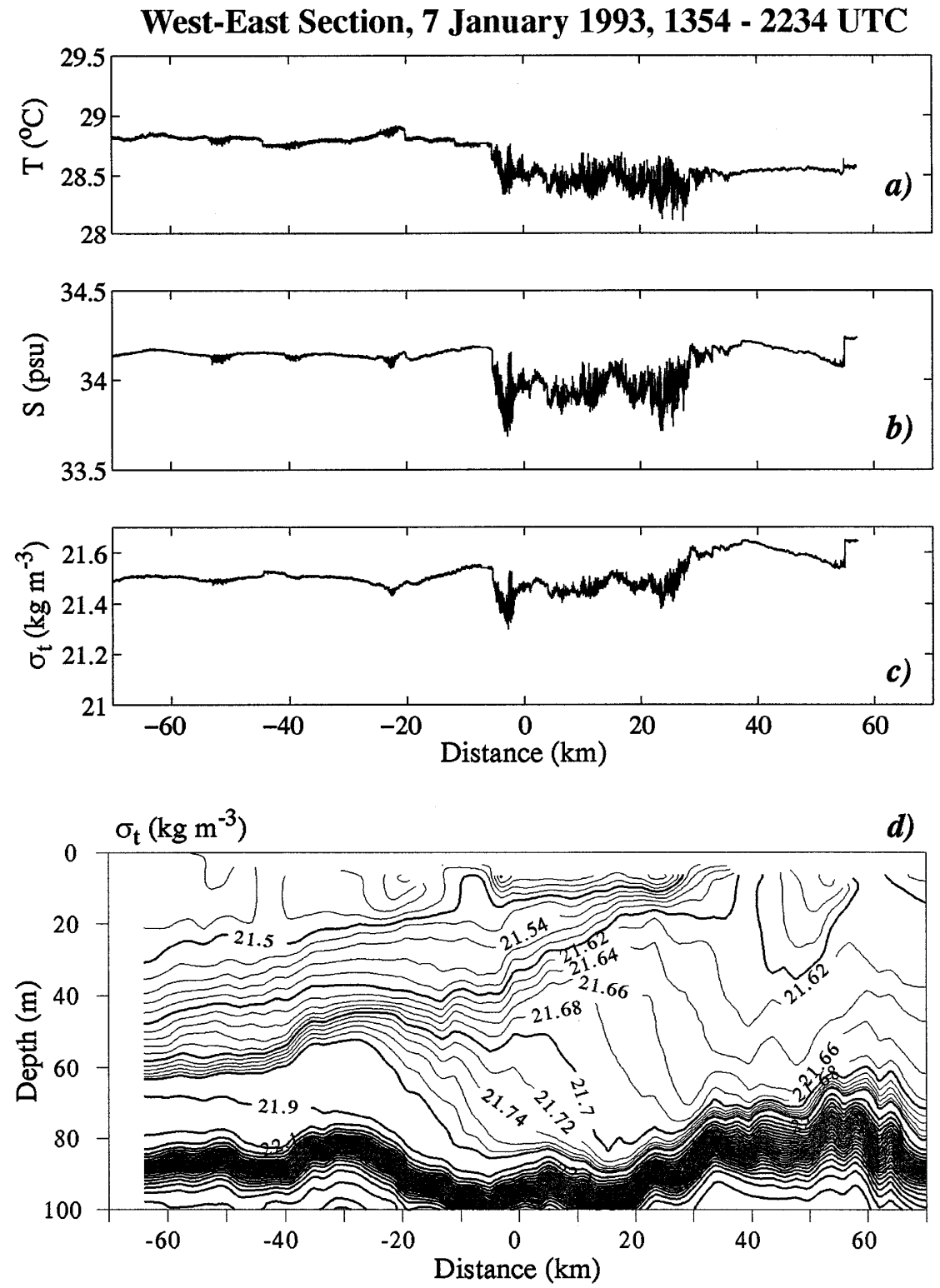

FIG. 10. Same as in Fig. 9 but for an east-west Wecoma section on 7 January 1993. Wind speed at $54.95 \mathrm{~km}$ (intersection of sharp frontal interface) is $1.5 \mathrm{~m} \mathrm{~s}^{-1}$, wind direction $200^{\circ}$. On contour plot (d), a several-meter thickness blank space near the ocean surface mainly results from a 5-m offset of the pressure sensor during this section, which occurred because of technical problems (see O'Malley et al. 1994).

Some evidence of enhanced vertical mixing during periods of strong winds was found by Samelson and Paulson (1988) in the eastern North Pacific subtropical frontal zone. Their analysis, however, resolved only scales no less than $100 \mathrm{~m}$ and therefore did not include the most sharp frontal interfaces.

For the case schematically shown in Fig. $11 \mathrm{a}$, the front cannot exist for a long time because the increased entrainment rate results in relatively fast erosion of the density anomaly associated with the sharp frontal interface. A dynamically inactive interface (in which sa- linity compensates temperature in the density field) can, however, exist for a long time even with an opposing wind because no additional convective mixing occurs. This explains why, under an opposing wind, we mainly find inactive sharp frontal interfaces in the near-surface layer of the ocean (see example in Fig. 7).

We can parameterize the effective viscosity within the frontal interface in the following way:

$$
\nu_{e} \approx \nu_{s}+\nu_{c} \text {. }
$$

The shear-induced turbulent viscosity 

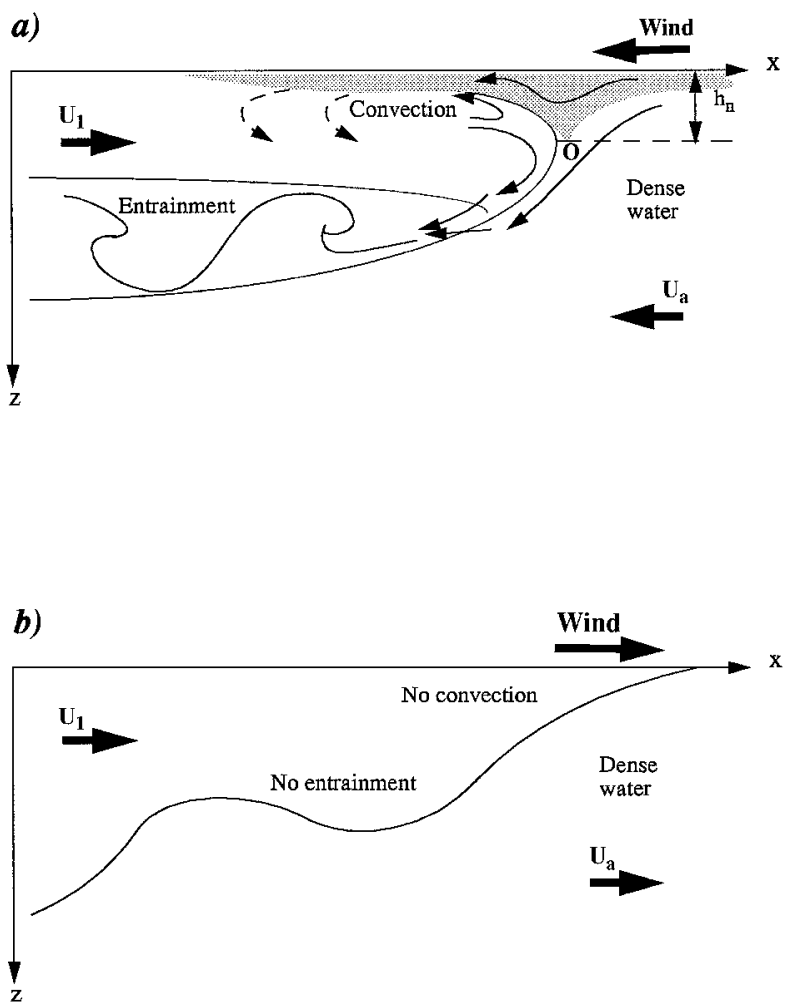

FIG. 11. Two different cases of interaction of frontal interfaces with wind stress, one with wind in opposite direction (a) and one with wind in the same direction (b): $\mathbf{U}_{1}$ is the velocity of the buoyancydriven current, $\mathrm{O}$ is its foremost point, and $\mathbf{U}_{\mathbf{a}}$ is the velocity of the ambient (wind drift) current. The shaded fluid passes above the head.

$$
\nu_{s}=\kappa u_{*} h,
$$

where $u_{*}=(\tau / \rho)^{1 / 2}, \tau$ is the momentum flux at the ocean-air interface, $\rho$ is the water density, the von Kármán's constant $\mathrm{k}=0.4$, and $h$ is the depth of the mixed layer. The convectively induced viscosity $\nu_{c}=w_{*} h$, where $w_{*}$ is the convective velocity scale. The convective term, $\nu_{c}$, is a nonzero value only in case (a). Following Priestly (1959) we can specify the convective velocity scale with $B_{0}$ denoting the vertical buoyancy flux by the formula,

$$
w_{*}=\left(h B_{0}\right)^{1 / 3} \text {. }
$$

A simple estimation of $B_{0}$ can be obtained by vertical integration of the advective near-surface flow of more dense water via the front. Dense water flux between the surface and the nose is directed inside the front (see diagram in Fig. 11a). In the coordinate system connected with the moving front,

$$
B_{0} \approx \frac{1}{L} \int_{0}^{h_{n}} g^{\prime} U(z) d z
$$

where $h_{n}$ is the depth of the foremost point - the noseand $L$ is the width of the front. According to laboratory experiments of Simpson and Britter (1979) the height of the nose is about $1 / 8$ the height of the gravity current head.

The depth of the nose is assumed to depend on the frictional velocity $u_{*}$ and on the reduced gravity $g^{\prime}: h_{n}$ $=$ function $\left(u_{*}, g^{\prime}\right)$. Standard dimensional analysis results in the following formula:

$$
h_{n} \approx a \frac{u_{*}^{2}}{g^{\prime}},
$$

where $a$ is the dimensionless coefficient. We have derived from Figs. 5, 7, and 9 of the Simpson and Britter (1979) laboratory experiment (at $h_{4} / h_{1} \approx 0.05$ and at the Reynolds number of the gravity current head $\operatorname{Re}_{h}>$ $10^{3}$ ) that

$$
h_{n} \approx 0.5 \frac{U_{1}^{2}}{g^{\prime}},
$$

where $U_{1}$ is the velocity of the gravity current head. The friction velocity in the Simpson and Britter (1979) laboratory gravity current can be calculated using the bulk formula, $u_{*}^{2}=C_{0} U_{1}^{2}$, where the drag coefficient estimate is $C_{0} \approx 2 \times 10^{-3}$ (Csanady 1978). Ultimately, an estimate $a \approx 0.5 C_{0}^{-1}$ can be obtained by comparison (7) with the laboratory simulation of gravity currents by Simpson and Britter (1979).

Dependence (7) can be extended for the cases when the wind direction is not perpendicular to the buoyant spreading of the front by substituting dimensionless coefficient $a$ by $a_{\theta}$;

$$
a_{\theta} \approx a \frac{\cos \theta+|\cos \theta|}{2},
$$

where $\theta$ is the wind direction relative to the direction of buoyant spreading of the front. According to (8) at $\theta>90^{\circ}$ or $\theta<-90^{\circ} h_{n} \equiv 0$ (because no convective instability occurs when the wind direction has no component against the buoyant spreading of the front).

Assuming that in the coordinate system moving with the nose, the current velocity profile above the nose is

$$
U(z) \approx-U_{0}\left(1-\frac{z}{h_{n}}\right)^{4}
$$

(Simpson and Britter 1979) and $U_{0} \approx 1.2\left(g^{\prime} \mathrm{h}\right)^{1 / 2}$, Eqs. (5), (6), and (8) reduce to the following form:

$$
w_{*}=\left(0.24 a_{\theta} \frac{u_{*}^{2}}{g^{\prime} L}\right)^{1 / 3}\left(g^{\prime} h\right)^{1 / 2}
$$

Combining (3), (4), and (9) we obtain

$$
\nu_{e} \approx \kappa u_{*} h+\left(0.24 a_{\theta} \frac{u_{*}^{2}}{g^{\prime} L}\right)^{1 / 3} h\left(g^{\prime} h\right)^{1 / 2}=\kappa u_{*} h f,
$$

where

$$
f=1+\left(0.24 a_{\theta} \frac{u_{*}^{2}}{g^{\prime} L}\right)^{1 / 3} \frac{\left(g^{\prime} h\right)^{1 / 2}}{\kappa u_{*}}
$$




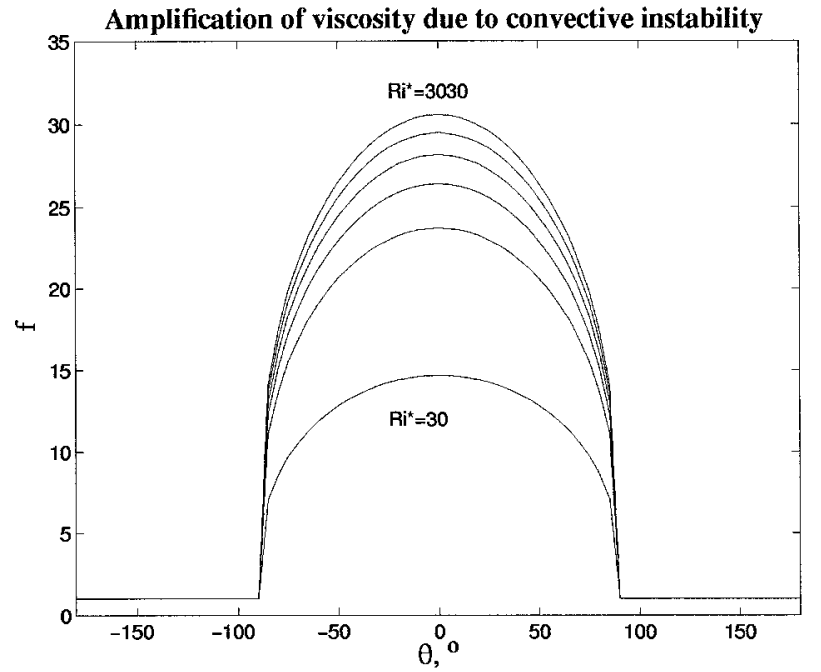

FIG. 12. Amplification factor $f$ of effective viscosity due to convective mixing across sharp frontal interface, calculated at different values of the Richardson-type number, $\mathrm{Ri}_{*}=g^{\prime} h / u_{*}^{2}$. Theta is the wind direction relative to the direction of buoyant spreading of the front.

is the "amplification factor" describing the increase of the effective viscosity in the near-surface layer of the ocean due to convective mixing associated with winddriven horizontal advection of more dense water.

Criterion (2) can be rewritten now in the following way:

$$
\mathrm{Re}_{*}=\frac{\mathrm{Ri}_{*}^{1 / 2}}{\kappa f},
$$

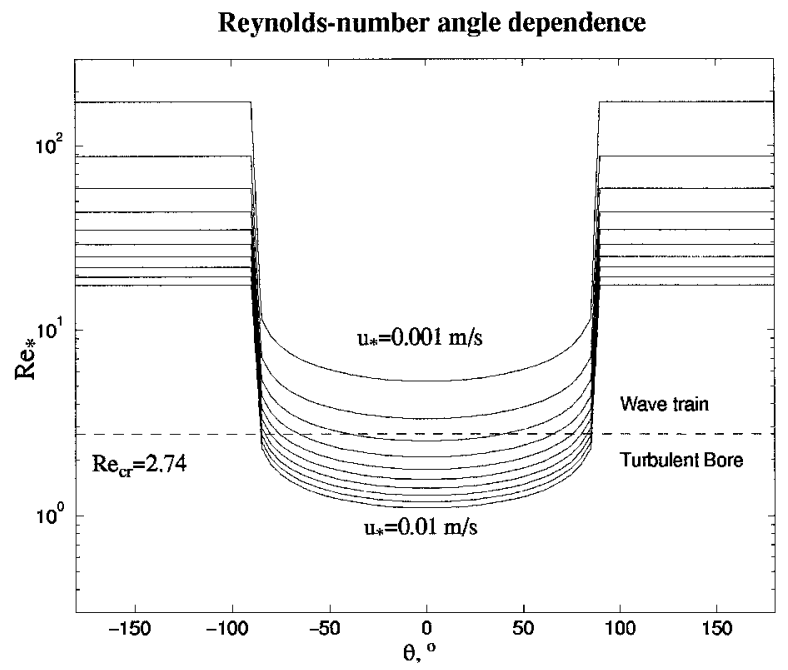

FIG. 13. Dependence of Reynolds-type number $\mathrm{Re}_{*}$ on wind direction relative to the direction of buoyant spreading of the front $\theta$, being calculated at values of friction velocity $u_{*}$ from 0.001 to 0.01 $\mathrm{m} \mathrm{s}^{-1}$ in steps of $0.001 \mathrm{~m} \mathrm{~s}^{-1}$. The upper and lower curves appropriate correspondingly. Dashed line represents critical value of the Reynolds-type number.

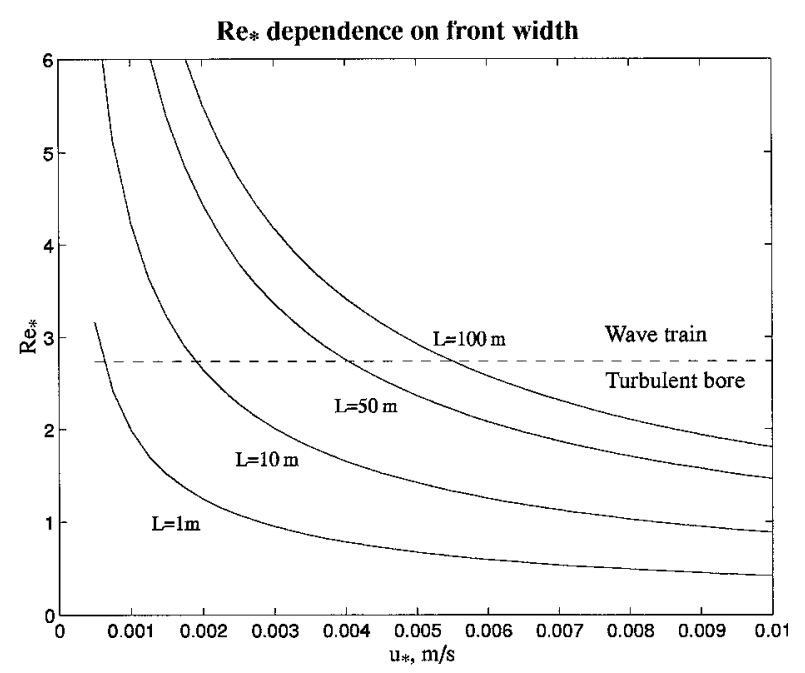

FIG. 14. Dependence of Reynolds-type number $\mathrm{Re}_{*}$ on frictional velocity $u_{*}$ at different width $L$ of frontal interface. Dashed line represents critical value of the Reynolds-type number, $\operatorname{Re}_{\mathrm{cr}}=2.74$.

where $\mathrm{Ri}_{*}=g^{\prime} h / u_{*}^{2}$ is a Richardson-type number, and the amplification factor can be expressed as

$$
f=1+\left(0.24 \frac{a_{\theta} h}{\kappa^{3} L}\right)^{1 / 3} \mathrm{Ri}_{*}^{11 / 6} .
$$

Figure 12 shows dependences (13) for the amplification factor $f$ for the typical values $h=10 \mathrm{~m}$ and $L=20 \mathrm{~m}$, at several values of $\mathrm{Ri}_{*}$ number within the range $30<$ $\mathrm{Ri}_{*}<3030$. The amplification factor $f$ achieves substantial value at large $\mathrm{Ri}_{*}$ and $\theta=0$.

Figure 13 demonstrates dependence (12) for $h=10$ $\mathrm{m}, L=20 \mathrm{~m}$, and $\Delta \sigma_{t}=0.05 \mathrm{~kg} \mathrm{~m}^{-3}$ for the friction velocities within the range $0.001 \mathrm{~m} \mathrm{~s}^{-1}<u_{*}<0.01 \mathrm{~m}$ $\mathrm{s}^{-1}$. A solution of Eq. (B4) (see appendix B) in the form of the turbulent bore occurs when $\operatorname{Re}_{*}<\operatorname{Re}_{\text {cr }} \approx 2.74$. According to Fig. 13, the turbulent bore is possible when the wind opposes the buoyant spreading of the front. Under low wind speed conditions or in the case when the wind speed is directed along the direction of buoyant spreading of the front, $\mathrm{Re}_{*}>\mathrm{Re}_{\mathrm{cr}}$ and the solution of Eq. (B4) is of the wave train type.

For the observations of the sharp frontal interface shown in Figs. 9 and 10, Reynolds number $\mathrm{Re}_{*}$ is equal to 60 and 130 correspondingly. In both cases $\operatorname{Re}_{*} \gg \operatorname{Re}_{\text {cr }}$ and no turbulent bore is predicted; this corresponds to favorable conditions for the appearance of sharp frontal interfaces. Dependence of the Reynolds-type number $\mathrm{Re}_{*}$ on frictional velocity $u_{*}$ at different widths of the frontal region is shown in Fig. 14 for $h=10 \mathrm{~m}$ and $\Delta \sigma_{t}=0.05$ $\mathrm{kg} \mathrm{m}^{-3}$. Increase of the frontal width results in an increase of the critical friction velocity at which the wavelike solution of (B4) transits into a borelike type. 


\section{Discussion}

\section{a. Comparison of model and experimental data}

The most important results of the observations described in section 3 are the following:

1) Horizontal profiles of $T, S$, and $\sigma_{t}$ in the warm pool area sometimes reveal strongly asymmetrical disturbances on scales of $0.2-60 \mathrm{~km}$; gradual rise of the density is followed by its abrupt decrease (or vice versa depending on the ship direction). The width of the sharp frontal interface is sometimes only $\sim 1.5$ $\mathrm{m}$.

2) Occurrence of the sharp frontal interface depends on its orientation relative to the wind direction rather than on the wind speed magnitude (Fig. 8). The sharp frontal interfaces in density are mainly observed when the wind stress is along the buoyant spreading direction. When the wind stress is in an opposite direction relative to the buoyant spreading of the front, the observed sharp frontal interfaces are usually compensated in density.

These experimental facts are consistent with the model considered in section 5. The observed asymmetrical structures in the near-surface layer of the ocean may be explained by an internal bore developing on the nearsurface density anomaly. This anomaly is formed because of precipitation effects, solar warming, and so forth. The shallow-water model describes the evolution of an initially smooth disturbance into a borelike structure. Except for conditions of very low wind speed or large density difference across the sharp frontal interface, this model predicts spatial anisotropy of the wind mixing efficiency in the frontal region relative to the wind direction (Fig. 13). This corresponds to the observations of the sharp frontal interfaces in the COARE EQ-3 cruise showing the spatial anisotropy relative to the wind direction.

Dewar (1991, 1992), Marshall and Nurser (1991), and Nurser (1995) developed a so-called shock front model. A shock front may form where the convergence is a consequence of some property gradient. With time, the property gradient sharpens itself into a discontinuity, and a shock front develops. This is the same idea as in our model but applied for the "planetary geostrophic" equations, that is, when both $\beta$ and $f$ baroclinic Rossby numbers are small. The model yields climatic fronts like the subtropical front on the southern flank of the subtropical gyre. Our model of the sharp frontal interfaces is the "buoyant" asymptotics of the problem, neglecting the rotational effects. This corresponds to the large $\beta$ and $f$ baroclinic Rossby numbers, with

$$
L \ll\left(\frac{c}{2 \beta}\right)^{1 / 2} \text { and } L \ll \frac{c}{f},
$$

where $\beta=(\partial f / \partial y)_{\phi=0}=2.3 \times 10^{-11} \mathrm{~m}^{-1} \mathrm{~s}^{-1}, f$ is the Coriolis parameter, and $c$ is the phase speed of internal perturbations in the near-surface layer of the ocean. For the length scale of the observed asymmetrical structures $L \approx 0.2-60 \mathrm{~km}$, both the $\beta$ and $f$ baroclinic Rossby numbers are typically large but may sometimes reduce to the order of unity. A considerable vorticity of the density feature associated with the sharp frontal interface (Figs. 9 and 10) also suggests possible importance of rotational effects. The more complete model of the sharp frontal interfaces should therefore include both buoyant and rotational effects.

The Chen and Young (1995) statistical model incorporating nonlinear mixing predicts the density-compensated temperature and salinity gradients as dominating in mixed layer fronts. The model, however, does not include wind stress effects, which are important in case of the sharp frontal interfaces.

\section{b. Estimate of entrainment rates}

The appearance of sharp frontal interfaces is an indication of an active detrainment and water subduction within the mixed layer. The subduction is an important process in forming the barrier layer in the warm pool area (Shinoda and Lukas 1995; VD97). According to our model, favorable conditions for the subduction are the case when no turbulent bore occurs, that is, when the wind is either weak or directed along the buoyant spreading of the front.

In the opposite case, the turbulent entrainment via the sharp frontal interface may be substantial. We have already mentioned in section $5 \mathrm{c}$ that the entrainment flux can achieve 0.15 times the mass flux of the buoyancydriven current itself (Simpson 1987). The entrainment density flux associated with the wind opposing a series of the buoyancy spreading fronts is equal to

$$
D_{h} \approx 0.15 \Delta \rho U \frac{h}{L_{0}}=0.15 \Delta \rho\left(g^{\prime} h\right)^{1 / 2} \frac{h}{L_{0}},
$$

while the vertical entrainment flux is $D_{v} \approx \Delta \rho w_{e}$. Here $L_{0}$ is the distance between the sharp frontal interfaces and $w_{e}$ is the entrainment velocity that can be parameterized for the shear flow over the range $30<\mathrm{Ri}_{*}$ $<300$ (Kato and Phillips 1969): $w_{e}=2.5 u_{*} \mathrm{Ri}_{*}^{-1}$, where $\mathrm{Ri}_{*}=g^{\prime} h / u_{*}^{2}$. The ratio of horizontal to vertical entrainment flux is the following:

$$
\frac{B_{h}}{B_{\nu}} \approx 0.072 \operatorname{Ri}^{3 / 2} * \frac{h}{L_{0}} .
$$

According to (14), for $B_{h}=B_{v}, h=10 \mathrm{~m}, g^{\prime}=0.001$ $\mathrm{m} \mathrm{s}^{-2}$, and $u_{*}=0.01 \mathrm{~m} \mathrm{~s}^{-1}: \mathrm{Ri}_{*}=100$ and $L_{0} \approx 0.72$ $\mathrm{km}$. The same estimation under low wind speed conditions at $u_{*}=0.0025 \mathrm{~m} \mathrm{~s}^{-1}$ results in $L_{0} \approx 46 \mathrm{~km}$, which is close to the equatorial Rossby radius for the near-surface pycnocline, $R_{\beta} \approx 50 \mathrm{~km}$. This means that under low wind speed conditions turbulent entrainment via the sharp frontal interfaces may be an appreciable factor in the heat and mass exchange within the upper 
layer of the ocean if the internal bore develops. On the other hand, when the wind is weak, the internal bore can develop only on the interfaces with sufficiently small density differences (Fig. 13).

\section{Conclusions}

High-resolution measurements in the equatorial western Pacific warm pool have revealed numerous cases of periodic sharp frontal interfaces in the near-surface layer of the ocean. The sharp frontal interfaces have been observed in frontal regions and on the periphery of the freshwater puddles. The structural form of these interfaces has some similarity to that of the internal surge or the internal bore previously observed in long stably stratified lakes, in straits, and in shallow coastal waters. We have found an anisotropy of the interfaces with respect to the wind direction and confirmed it by a statistically representative dataset, which included 30 days of almost continuous recording by the bow sensors and a thermosalinograph.

To explain the observations, we have followed a hypothesis that the sharp frontal interfaces in the warm pool area may appear as a result of nonlinear buoyant adjustment of near-surface stably stratified layers of the ocean to the external forcing. The latter may include the variable buoyancy flux and wind stress at the oceanair interface, tidal motions, and so forth. The horizontal scale of the observed asymmetrical structures (0.2-60 $\mathrm{km}$ ) does not exceed either the $\beta$ or $f$ baroclinic Rossby radius estimated for the near-surface pycnocline in the equatorial warm pool. We therefore explore a buoyant asymptotics of the problem, neglecting the influence of rotational effects. Comparison with laboratory studies of the gravity currents may explain the observed anisotropy of the sharp frontal interfaces with respect to the wind direction. When the wind stress has a component along the buoyant spreading direction of the front, the latter has some analogy to an arrested wedge. When the wind opposes the buoyant spreading of the front, the frontal region is intensively mixed and with time the interface either achieves a density compensated state or degrades.

The generation of asymmetrical structures has been explored using a shallow-water model including both dissipation and dispersion. The model predicts evolution of an initially smooth disturbance of the near-surface pycnocline into a shock-wave structure. A Reynoldstype number is the criterion of transition from wave train solution to dissipative shock-wave structure. The model also predicts a spatial anisotropy of the frontal interfaces with respect to the wind direction that is in agreement with the field data.

Acknowledgments. Michael Gregg suggested inclusion of this work for the TOGA COARE planners. Bob Weisberg, Rick Cole, and Linda Mangum kindly included the bow measurements in the program MW9410 and MW9411 COARE cruises of the R/V Moana Wave. We gratefully acknowledge COARE collaborators Peter Hacker, Adriana Huyer, Clayton Paulson, and Michael Kosro for SEASOAR and bow data from Wecoma COARE IOP-2 leg. Anatoli Arjannikov, Mark Baker, and Jefrey Snyder provided technical support of the bow measurements in Moana Wave legs. Sharon DeCarlo and Dmitry Khlebnikov wrote software for recording and preliminary processing of the data. The assistance of the crew of the R/V Moana Wave and Wecoma was crucial for success of the program. Discussion of the first observations of the sharp frontal interfaces with Grigory Barenblatt, Andrei Zatsepin, and David Farmer by one of the authors (AS) was important for the physical explanation of the observations. The study was supported by the NSF Grants OCE-9216891 and OCE9113948 and by the ONR Grant N00014-961-0832.

\section{APPENDIX A \\ Algorithm for Detection of Sharp Frontal Interfaces}

The algorithm is applied to an $8-\mathrm{Hz}$ decimated record of density from the bow sensors. At first, the algorithm reduces noises by applying a median third-order filter and a linear fifth-order filter with Hamming window. Then, it looks for the areas where the absolute value of the density gradient,

$$
\left|\frac{d \sigma_{t}}{d l}\right|>n \cdot \operatorname{std}\left(\frac{d \sigma_{t}}{d l}\right),
$$

where $l$ is the horizontal distance and std is the standard deviation determined on a 10-min segment. Coefficient $n$ is an adjustable parameter. We used values of $n$ as large as 4 to detect only the most sharp frontal interfaces.

Strong variability of the density signal may be caused also by the near-surface vertical stratification on account of depth variation of the bow sensors. To distinguish horizontal features from the vertical ones, the algorithm determines mean level of density and standard deviation of density fluctuations $12.5 \mathrm{~s}$ before and $12.5 \mathrm{~s}$ after the area with anomalous density gradient. The sharp frontal interface is detected if the empirical criteria

$$
\Delta \sigma_{t}>(n+1) \frac{\left(\operatorname{std}_{1}\left(d \sigma_{t} / d l\right)+\operatorname{std}_{2}\left(d \sigma_{t} / d l\right)\right)}{2}
$$

is performed, where $\Delta \sigma_{t}$ is the density difference across the frontal interface, $\mathrm{std}_{1}$ and $\mathrm{std}_{2}$ are the standard deviations on 12.5-s segments correspondingly before and after the area with anomalous density gradient.

APPENDIX B

\section{Evolution of a Long-Wave Disturbance on an Intermediate Pycnocline}

We consider a shallow water approximation (Long 1972; Whitham 1974; Farmer 1978; Barenblatt and Sha- 
piro 1984). Evolution of perturbations with wavelengths $L \gg h$, where $h$ is the depth of an intermediate pycnocline can be described in the framework of shallowwater theory similar to the analysis of Farmer (1978) for long stably stratified lakes. Following Farmer (1978) we use dimensionless wave and time coordinates, $y=$ $(x-c t) / L$, and $\tau=c t / L$, where $x, t$, and $c$ are the horizontal coordinates in the direction of propagation of the internal perturbation, $t$ is time, $c$ is the phase speed, and $L$ is a horizontal length scale for the perturbation. The nonlinear evolution of the internal disturbance can be described by the Korteweg-deVries equation (Farmer 1978)

$$
\eta_{\tau}-p \eta \eta_{y}+q \eta_{y y y}=0
$$

where $p$ and $q$ are constants. For a two-layer Boussinesq system with mean shear, Farmer (1978) obtained the following expressions:

$$
p=\frac{3}{2} \frac{(H-h)}{H h}, \quad q=\frac{1}{6} \frac{H h}{L^{2}},
$$

where $H$ is the thickness of the lower layer and $h$ is the thickness of the upper layer. In the early stages of evolution the dispersive term may be dropped (Long 1972) and (B1) reduces to

$$
\eta_{\tau}-p \eta \eta_{y}=0
$$

Equation (B2) is a well-known nonlinear equation. According to it, an initially symmetrical perturbation will evolve into strongly asymmetrical structure (see Long 1972; Farmer 1978).

At the stage of development of the perturbation when one of its slopes becomes very steep, the dispersive term in (B1) will start to interact with the nonlinear term. Further evolution of the system will also depend on dissipation effects that are not described by Eq. (B1). Whitham (1974) and Barenblatt and Shapiro (1984) used an equation of the Korteweg-deVries-Burgers type to understand the role of dispersion and dissipation in such a nonlinear system;

$$
\eta_{t}+c_{0}\left(1+\frac{3}{2} \frac{\eta}{h}\right) \eta_{x}+\frac{1}{6} c_{0} h^{2} \eta_{x x x}=\nu_{e} \eta_{x x},
$$

where $t$ is the time, $x$ is the horizontal coordinate, and $h$ is the undisturbed depth of near-surface pycnocline (for simplicity, here it is assumed that $h \ll H$ ), $c_{0}=$ $\left(g^{\prime} h\right)^{1 / 2}, g^{\prime}$ is the reduced gravity, and $\nu_{e}$, is the effective (turbulent) viscosity.

Steady propagating solutions of (B3) are being found in the form $\eta=h \zeta(X), X=x-U t$, where $U$ is the propagation speed of the disturbance. Integration of the appropriate differential equation for $\zeta$ at $\zeta \rightarrow 0$ as $X \rightarrow$ $\infty$ results in (Whitham 1974)

$$
\frac{1}{6} h^{2} \zeta_{X X}-\frac{\nu_{e}}{c_{0}} \zeta_{X}+\frac{3}{4} \zeta^{2}-\left(\frac{U}{c_{0}}-1\right) \zeta=0,
$$

which can be normalized in the following way:

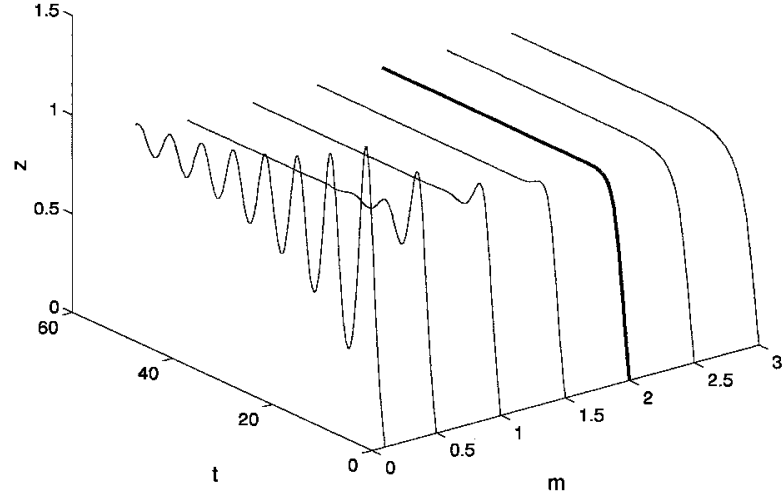

FIG. B1. Solution of Eq. (B5) at different values of parameter $m$.

$$
z_{\xi \xi}-m z_{\xi}+z^{2}-z=0
$$

where

$$
\begin{gathered}
\xi=\{6(F-1)\}^{1 / 2} \frac{X}{h_{0}}, \quad z=\frac{3}{4(F-1)} \zeta, \quad F=\frac{U}{c_{0}}, \\
m=\left(\frac{6}{F-1}\right)^{1 / 2} \operatorname{Re}_{*}^{-1},
\end{gathered}
$$

and

$$
\operatorname{Re}_{*}=\frac{h\left(g^{\prime} h\right)^{1 / 2}}{\nu_{e}}
$$

Here $\mathrm{Re}_{*}$ is a dimensionless number of the Reynolds type proposed for analysis of a nonlinear system (B3) by Barenblatt and Shapiro (1984).

Figure B1 shows solutions of nonlinear Eq. (B5) for different values of parameter $m$ obtained by using the Matlab Simulink. At $m<2$ the solution is oscillatory and at $m>2$ it is not oscillatory. The solution for the critical value $m=2$ is shown by a heavy line.

According to (B6)-(B7), the critical value of $m=2$ at Whitham's (1974) critical Froude number of $F=1.2$ corresponds to the following criteria for the Reynolds type number $\mathrm{Re}_{*}=\mathrm{Re}_{\mathrm{cr}} \approx 2.74$. So, according to (B6) for $\operatorname{Re}_{*}>2.74$, the solution of (B4) is expected to be of a wavelike nature (and finally evolve into a series of solitons) and of a turbulent nature (and finally evolve into a dissipative shock-wave structure) for $\mathrm{Re}_{*}<2.74$.

\section{REFERENCES}

Alpers, W., and E. J. Salusti, 1983: Scylla and Charybdis observed from space. J. Geophys. Res., 88, 1800-1808.

Anderson, S. P., R. A. Weller, and R. Lukas, 1996: Surface buoyancy forcing and the mixed layer of the western Pacific warm pool: Observations and 1-D model results. J. Climate, 9, 3056-3085.

Ando, K., and M. J. McPhaden, 1995: Variability of surface layer hydrography in the tropical Pacific Ocean. J. Geophys. Res., in press.

Apel, J. R., J. R. Holbrook, A. K. Liu, and J. J. Tsai, 1985: The Sulu Sea internal soliton experiment. J. Phys. Oceanogr., 15, 16251651. 
Barenblatt, G. I., and G. I. Shapiro, 1984: A contribution to the theory of the wave fronts in dispersive dissipative media. Izv. Akad. Nauk SSSR, Atmos. Oceanic Phys., 20, 277-284.

Csanady, G. T., 1978: Turbulent interface layers. J. Geophys. Res., 83, 2329-2342.

Chen, L., and W. R. Young, 1995: Density compensated thermohaline gradients and diapicnical fluxes in the mixed layer. J. Phys. Oceanogr., 25, 3064-3075.

Dewar, W. K., 1991: Arrested fronts. J. Mar. Res., 49, 21-52.

- 1992: Spontaneous shocks. J. Phys. Oceanogr., 22, 505-522.

Farmer, D. M., 1978: Observations of long nonlinear internal waves in a lake. J. Phys. Oceanogr., 8, 63-73.

— , and J. R. Gemmrich, 1996: Measurements of temperature fluctuations in breaking surface waves. J. Phys. Oceanogr., 26, 816825.

Fozdar, F. M., G. J. Parker, and J. Imberger, 1985: Matching temperature and conductivity sensor response characteristics. $J$. Phys. Oceanogr., 15, 1557-1569.

Halpern, D., 1971: Observations on short period internal waves in Massachusetts Bay. J. Mar. Res., 29, 116-132.

Haury, L. R., M. G. Briscoe, and M. H. Orr, 1979: Tidally generated internal wave packets in Massachusetts Bay. Nature, 278, 312 317.

Hunkins, K., and M. J. Fliegel, 1973: Internal undular surges in Seneca Lake: Natural occurrence of solitons. J. Geophys. Res. 78, 539-548.

Huyer, A., P. M. Kosro, R. Lukas, and P. Hacker, 1996: Upper-ocean thermohaline fields near $2^{\circ} \mathrm{S}, 156^{\circ} \mathrm{E}$ during TOGA-COARE, November 1992 to February 1993. J. Geophys. Res., in press.

Kato, H., and O. M. Phillips, 1969: On the penetration of a turbulent layer into a stratified fluid. J. Fluid Mech., 37, 643-655.

Kinder, T. H., 1984: Net mass transport by internal waves near the Strait of Gibraltar. Geophys. Res. Lett., 11, 987-990.

Lee, C. Y., and R. C. Beardsley, 1974: The generation of long nonlinear internal waves in a weakly stratified shear flow. J. Geophys. Res., 79, 453-462.

Long, R. R., 1972: The steepening of long internal waves. Tellus, 8 , 88-99.

Lukas, R., and E. Lindstrom, 1991: The mixed layer of the western equatorial Pacific Ocean. J. Geophys. Res., 96 (Suppl.), 33433358 .

_ , and P. Hacker, 1995: Spinup of submesoscale eddy in the TOGA COARE Intensive Flux Array during the spindown of an intense eastward jet. Abstract, TOGA 95 Int. Sci. Conf. on Tropical Oceans Global Atmosphere, Melbourne, Australia, 248-249.

Marshall, J. C., and A. J. G. Nurser, 1991: A continuously stratified thermocline model incorporating a mixed layer of variable thickness and density. J. Phys. Oceanogr., 21, 1780-1792.

Moore, D. W., and S. G. H. Philander, 1977: Modeling of the tropical ocean circulation. The Sea, E. D. Goldberg I. N. McCave, J. J. O'Brien, and J. H. Steele, Eds., Vol. 6, Wiley Interscience, 319361.

Nurser, A. G., 1995: Stationary shock fronts in a continuously stratified thermocline model. J. Phys. Oceanogr., 25, 3132-3147.

O’Malley, R., P. M. Kosro, R. Lucas, and A. Huyer, 1994: Seasoar observations during a COARE Surveys cruise, W9211B, 12 December 1992 to 16 January 1993. Data Rep. 156, Ref. 94-2, 426 pp. [Available from Dr. Adriana Huyer, College of Ocean and Atmospheric Sciences, Oregon State University, Ocean Admin Bldg 104, Corvallis, OR 97331-5503.]

Osborne, A. R., and T. L. Burch, 1980: Internal solitons in the Andaman Sea. Science, 208, 451-460.

Paulson, C. A., and G. Largerloef, 1993: Fresh surface lenses caused by heavy rain over the western Pacific warm pool during TOGA COARE. Eos Trans. Amer. Geophys. Union, 75, 125.
Picaut, J., L. Gourdeau, A. J. Busalacchi, F. I. Gonzalez, and M. J. McPhaden, 1995: Evidence of surface-to-bottom internal tide in the COARE domain. TOGA COARE Int. Data Workshop (Touluse, France, 2-11 August 1994), Summary Rep. [Available from TCIPO, UCAR, P.O. Box 3000, Boulder, CO 80307-3000.]

Pinkel, R., M. Merrifield, S. Rutledge, W. Petersen, D. Siegel, and L. Washburn, 1994: Fine-scale observations of the upper ocean during the IOP: A view from Doppler sonar and radar. TOGA COARE Int. Data Workshop, Touluse, France, 2-11 August 1994, Summary Rep., 140 pp. [Available from TCIPO, UCAR, P.O. Box 3000, Boulder, CO 80307-3000.]

Priestly, C. H. B., 1959: Turbulent Transfer in the Lower Atmosphere. University of Chicago Press, $130 \mathrm{pp}$.

Samelson, R. M., and C. A. Paulson, 1988: Towed thermistor chain observations of fronts in the subtropical North Pacific. J. Geophys. Res., 93, 2237-2246.

Shinoda, T., and R. Lukas, 1995: Lagrangian mixed layer modelling of the western equatorial Pacific. J. Geophys. Res., 100, 25232541.

— S. DeCarlo, S. Kennan, R. Lukas, F. Santiago-Mandujano, and J. Snyder, 1995: Shipboard measurements during COARE enhanced monitoring cruises. SOEST Tech. Rep. 95-07, 205 pp. [Available from Dept. of Oceanography, University of Hawaii, 1000 Pope Rd. Honolulu, HI 96822]

Simpson, J. E., 1987: Gravity Currents: In the Environment and the Laboratory. Ellis Horwood Limited, 244 pp.

- and R. E. Britter, 1979: The dynamics of the head of a gravity current advancing over a horizontal surface. J. Fluid Mech., 94, 477-495.

Soloviev, A. V., 1990: Coherent structure at the ocean surface in convectively unstable conditions. Nature, 346, 157-160.

— to wind forcing. Abstract, 24th Int. Liege Colloquium on Ocean Hydrodynamics: 'Sub-Mesoscale Air-Sea Interaction, Liege, Belgium, GHER/Model Environment, 99-100.

— , R. Lukas, S. DeCarlo, J. Snyder, A. Arjannikov, M. Baker, and D. Khlebnikov, 1995: Small-scale measurements near the oceanair interface during TOGA COARE. SOEST Tech. Rep. 95-05, 257 pp. University of Hawaii, [Available from Dept. of Oceanography, University of Hawaii, 1000 Pope Rd., Honolulu, HI 96822.]

Thorpe, S. A., 1971: Asymmetry of the internal seiche in Loch Ness. Nature, 231, 306-308.

_ 1985: Small-scale processes in the upper ocean boundary layer. Nature, 318, 519-522.

- A. Hall, and I. Crofts, 1972: The internal surge in Loch Ness. Nature, 237, 96-98.

Volkov, Ju. A., A. V. Soloviev, V. V. Turenko, V. A. Bezverkhnii, N. V. Vershinsky, and F. M. A. Ermolaev, 1989: Investigation of hydrophysical fields structure of the thin surface layer of the ocean from a moving vessel. Izv. Akad. Nauk SSSR, Atmos. Oceanic Phys., 25, 695-701.

Webster, P. J., and R. Lukas, 1992: TOGA COARE: The Coupled Ocean-Atmosphere Response Experiment. Bull. Amer. Meteor. Soc., 73, 1377-1416.

Whitham, G. B., 1974: Linear and Nonlinear Waves. Wiley, 636 pp.

Winant, C. J., 1974: Internal surges in coastal waters. J. Geophys. Res., 79, 4523-4526.

Yoder, J. A., S. G. Ackleson, R. T. Barber, P. Flament, and W. M. Blach, 1994: A line in the sea. Nature, 371, 689-692.

Zenk, W., and E. J. Katz, 1975: On the stationarity of temperature spectra at high horizontal wave numbers. J. Geophys. Res., 80, 3885-3891.

Ziegenbein, J., 1969: Short internal waves in the Strait of Gibraltar. Deep-Sea Res., 16, 479. 